\title{
Spatio-temporal assessment of pregnant women exposure to chlorpyrifos at a regional scale
}

Corentin Regrain ${ }^{1,2,3}$, Florence Anna Zeman ${ }^{4}$, Mohammed Guedda ${ }^{2}$, Karen Chardon ${ }^{5}$, Véronique Bach ${ }^{5}$, Céline Brochot ${ }^{4}$, Roseline Bonnard ${ }^{1}$, Frédéric Tognet $^{6}$, Laure Malherbe ${ }^{7}$, Laurent Letinois ${ }^{7}$, Emmanuelle Boulvert ${ }^{1}$, Fabrice Marlière ${ }^{8}$, François Lestremau ${ }^{9}$, Julien Caudeville $e^{*, 1,3}$

\section{* Correspondence: julien.caudeville@ineris.fr}

1 Institut National de l'Environnement Industriel et des Risques (INERIS), Unité Impact Sanitaire et Exposition (ISAE), Parc ALATA BP2, 60550 Verneuil-en-Halatte, France

2 LAMFA, UMR CNRS 7352, Université de Picardie Jules Verne, 33 rue Saint-Leu, 80039 Amiens, France

3 PériTox (UMR_I 01), INERIS/UPJV, Institut National de l'Environnement Industriel et des Risques (INERIS), Verneuil-en-Halatte, France

${ }^{4}$ Institut National de l'Environnement Industriel et des Risques (INERIS), Unité Toxicologie Expérimentale et Modélisation (TEAM), Parc ALATA BP2, 60550 Verneuil-en-Halatte, France ${ }^{5}$ PériTox (UMR_I 01), UPJV/INERIS, UPJV, Amiens, France

${ }^{6}$ Institut National de l'Environnement Industriel et des Risques (INERIS), Unité Modélisation Atmosphérique et Cartographie Environnementale (MOCA), Parc ALATA BP2, 60550 Verneuil-en-Halatte, France

${ }^{7}$ Institut National de l'Environnement Industriel et des Risques (INERIS), Unité Instrumentation et Exploitation de la Donnée (INDO), Parc ALATA BP2, 60550 Verneuil-en-Halatte, France 8 Institut National de l'Environnement Industriel et des Risques (INERIS), Unité Accompagnement à la surveillance de la qualité de l'air et des eaux de surfaces (ASUR), Parc ALATA BP2, 60550 Verneuil-en-Halatte, France 
${ }^{9}$ Institut National de l'Environnement Industriel et des Risques (INERIS), Unité Méthodes \& Développements en Analyses pour l'Environnement (ANAE), Parc ALATA BP2, 60550 Verneuil-en-Halatte, France

\section{Abstract}

Background: The aim of this study was to use an integrated exposure assessment approach, combining spatio-temporal modeling of environmental exposure and fate of the chemical to assess the exposure of vulnerable populations. In this study, chlorpyrifos exposure of pregnant women in Picardy was evaluated at a regional scale during one year. This approach provided a mapping of exposure indicators of pregnant women to chlorpyrifos over fine spatial and temporal resolutions using a GIS environment.

Methods: Fate and transport models (emission, atmospheric dispersion, multimedia exposure, PBPK) were combined with environmental databases in a GIS environment. Quantities spread over agricultural fields were simulated and integrated into a modeling chain coupling models. The fate and transport of chlorpyrifos was characterized by an atmospheric dispersion statistical metamodel and the dynamiCROP model. Then, the multimedia model Modul'ERS was used to predict chlorpyrifos daily exposure doses which were integrated in a PBPK model to compute biomarker of exposure (TCPy urinary concentrations). For the concentration predictions, two scenarios (lower bound and upper bound) were built.

Results: At fine spatio-temporal resolutions, the cartography of biomarkers in the lower bound scenario clearly highlights agricultural areas. In these maps, some specific areas and hotspots appear as potentially more exposed specifically in application period. Overall, predictions were closed to biomonitoring data and ingestion route was the main contributor to chlorpyrifos exposure.

Conclusions: This study demonstrated the feasibility of an integrated approach for the evaluation of chlorpyrifos exposure which allows the comparison between modeled predictions and biomonitoring data. 
Keywords: Exposure Modeling, PBPK Modeling, Multi-media Studies, Pesticides, Geospatial Analyses

\section{Introduction}

Amongst environmental stressors, chemical agents contribute to geographical environmental health inequalities regarding human exposures [1]. Exposure to chemical agents is complex to characterize due to the multiplicity of contamination sources and exposure pathways (ingestion, inhalation, dermal contact). Pollutant transfer processes into environmental media (air, soil, water) bring a spatial scope to exposure and involves territorial inequalities. Exposure is also time-varying and has potential impacts on people health during lifetime, which is included in the exposome concept [2]. In order to better understand the link between exposure to chemicals with potential health effects, variation of the exposure can be grasped by predicting representative internal doses and more specifically on target tissues of health effects [3].

Simultaneously, the cross-analysis of environmental, exposure and human biomonitoring data would enable to build a robust portrayal of the exposome, scalable on a large scale and at the populational level [3]. Integration of such data into a Geographic Information System (GIS) makes the link between source characterization and populational factors for a better understanding of the exposure [4]. Environmental data integration is however made difficult by the multitude of data produced according to specific objectives, with different levels of spatial and temporal aggregation, and requires specific methods and tools [5]. Combination of integrated environmental data with fate and transport modeling from the source to target population provides exposure predictions comparable to measurements in spatially and temporally consistent biological matrices. The comparisons of internal doses predictions with biomonitoring measurements provide the information to evaluate the relevance of the modeling approach. 
Pesticides constitute a relevant application to use a spatialized and integrated exposure assessment approach. Indeed, these substances, mainly used in agriculture for plant protection, are transferred to air, soil and water after spreading [6]. The ubiquitous nature of pesticides in the environment therefore constitutes a risk to human health [7]. Due to the agricultural use of these products, rural populations living near crop fields where pesticides are applied are likely to be more exposed [8]. The contamination of the atmospheric compartment by pesticides is much less known than soil and water contaminations. Most epidemiological studies start from the hypothesis that pesticide concentrations in air are higher near spreading areas and decrease with the distance [9]. The estimation of pesticide atmospheric emissions has long remained a blocking element for model implementation, due to the diversity of application modes, the dependence of meteorological conditions and the lack of knowledge about microphysics, depositions and remobilization processes. Thus, few studies use a spatial modeling of pesticide atmospheric dispersion [9]. Advances in this field and the possibilities of describing pesticide quantities on fine resolutions now allow the use of atmospheric models on a local scale [10]. In France, there are databases on environmental quality (air, soil, water) and human biomonitoring [11]. Several French studies (Elfe, Esteban) measured the level of exposure to chemicals including pesticides [12]. However, such surveys of representative samples are expensive and technically difficult to conduct in order to characterize the exposure at fine spatial resolutions and on large-scale territories.

As an example of active pesticide, Chlorpyrifos (O,O-diethyl O-3,5,6-trichloro-2-pyridinylphosphorothioate, CAS Registry No. 2921-88-2; CPF) belongs to the organophosphate class (OP). Since its first use in 1965, it has become one of the most widely used pesticides in the world and finds its main applications in agriculture and domestic use [13]. Human toxicological effects of OP insecticides are associated with the inhibition of acetylcholinesterase (AChE) in the brain and both central and peripheral nerve tissues [14]. Pregnant women are a vulnerable population as associations with prenatal exposure to chlorpyrifos were observed in 3 and 7 year-old children with an IQ and working memory abilities decrease $[15,16]$. Recent national 
studies and reports have shown general population exposure to chlorpyrifos and organophosphate pesticides in France and OECD countries [17-22]. In the study of Béranger et al. [22], TCPy, a metabolite of chlorpyrifos and a common biomarker of chlorpyrifos exposure used in human biomonitoring, was among the molecules measured in hair with the highest median concentrations, with value of $2.7 \mathrm{pg} / \mathrm{mg}$ of pregnant women hair.

In this context, this paper proposes to use an integrated exposure assessment approach, combining spatio-temporal modeling of environmental exposure and fate of the chemical to define relevant phenomena. The aim of this paper is to demonstrate the feasibility of our integrated methodology for chlorpyrifos exposure assessment. This methodology combines several transfer models with exposure models (multimedia, PBPK), integrates environmental databases and accounts for the spatio-temporal variability of the exposure. This approach provides a mapping of exposure indicators of pregnant women to chlorpyrifos over fine spatial and temporal resolutions using a GIS environment.

\section{Materials and methods}

\subsection{Case study}

Chlorpyrifos exposure was assessed in 2013 over the Picardy region in northern France. It is a moderately densely populated region, with an area of $19,399 \mathrm{~km}^{2}$ and almost 2 million inhabitants-3\% of France's population. Picardy is a region of field crops which highly consume pesticides [23]. Although chlorpyrifos has been progressively banned since 2013, resulting in a 97\% decrease in chlorpyrifos sales between 2013 and 2018, higher exposure to this chemical has been observed in 2013 [24, 25]. According to the French National Bank of Plant Protection Products Sales by Authorized Distributors (BNV-D), more than 12 tons of chlorpyrifos have been sold in the region and spread over 1.3 million hectares of agricultural land during this year, being used for cereal and vegetable crops, orchards and vineyards [25, 26]. 
Modeling of chlorpyrifos fate and transport between environmental compartments, exposure media and population has required the integration of databases (Table S1) allowing the characterization of pollutant sources in 2013 in Picardy such as the agricultural spreading [25], the meteorological parameters [27] and the environmental concentrations of substances in water and food products [28-30].

A deterministic approach integrating and coupling models with environmental data has been developed and applied on this study (Fig. 1). The models have been adapted to allow the integration of the output data of an upstream model as input data of the downstream model. One model assessed ambient air concentrations and deposits (far-field) by considering emission conditions either in gaseous or liquid aerosol phase and meteorological data (nearfield). Then, a multimedia model was used to predict pollutant transfers between each environmental compartment (water, air, soil) to predict external exposure resulting from the integration of all media concentrations [31-33]. In addition to this local exposure, the contribution of other exposure sources, e.g. non-local food products, were also accounted. Values of these exposures were then integrated in a PBPK model to predict internal exposure to chlorpyrifos (Fig. 1).

Chlorpyrifos exposure was assessed over a weekly time step and a regular grid with a spatial resolution of $4 \mathrm{~km}^{2}$. The regular grid constituted a common spatial support on which all the data were described. The following modeling approach therefore gave point estimates on grid cell centroids.

\subsection{Input data}

\subsubsection{Agricultural data}

Annual quantities applied over agricultural fields in Picardy in 2013 were predicted with data from the BNV-D [25]. Product sales extracted from this database were spatially distributed at field resolution using a methodology built by French National Institute for Agriculture, Food, and Environment (INRAE) according to the crop type and the postal code of the purchaser. 
Based on agricultural spreading times data provided by departmental agricultural chambers, quantities applied were predicted every three hours.

\subsubsection{Outdoor air}

Parameters including wind, temperature, precipitations, humidity and cloudiness available at a 3-hour frequency were extracted from the meteorological stations of Dieppe, Lille, Caen, Rouen and Orly, these framing the target region and describing a representative climate of northern France. Most notably for the atmospheric dispersion statistical model, the database of the Synop Essential network of surface stations of the World Meteorological Organization was used [27].

\subsubsection{Non-local food}

Concentrations of chlorpyrifos in non-local, i.e. commercial, food products came from French Total Diet Study (EAT2) and European Food Safety Authority's measurement compilations [28, 29]. Quantification frequencies of chlorpyrifos in commercial food products were very low (Table S2). Thus, two scenarios were determined to frame exposure to commercial products. The lower bound scenario (LB) is a minimalist scenario for which the undetected values are set to 0 and the values detected but not quantified are set to the limit of detection. The upper bound scenario (UB) is a maximalist scenario for which the undetected values are set to the limit of detection and the values detected but not quantified are set to the limit of quantification. The values used in the upper bound scenario correspond to the maximum chlorpyrifos concentrations measured in commercial food products.

\subsection{Fate and transport modeling approach}

\subsubsection{Air concentrations and atmospheric deposits}

Based on data from the BNV-D, departmental agricultural chambers and the simulations of the quantities applied at a 3-hour step, the distributions on soil, plant and air (drift) in the first minutes after spreading were predicted from PestLCl 2.0 [34] for each agricultural field in 
Picardy concerned by chlorpyrifos use. Emission fluxes from soil and plant volatilization were predicted with dynamiCROP [31, 32]. Air drift for this short period, as well as emission fluxes, then fed the atmospheric dispersion model described below.

The large number of parcels, their heterogeneous boundaries and the strong temporal variability of emissions have driven the modeling approach towards a machine learning approach and the development of a statistical metamodel. A database resulting from ADMS (Numtech, version 5.2) simulations, including gaseous and liquid aerosol deposits on ground and air concentrations, was thus constituted based on emissions of one basic parcel (100 per $100 \mathrm{~m}$ ) and meteorological parameters observed at surface stations [27]. Additional meteorological parameters such as the Monin-Obukhov length and the boundary layer height were calculated and enrich the description of each calculation result so that they can be used as explanatory variables for the learning of the statistical model. The size of aerosols considered for modeling liquid phase drift was set at the lowest value found in the literature [35], i.e., a minimum particle size of $50 \mu \mathrm{m}$, in order to give preference to a major atmospheric transport approach. Once the metamodel was calibrated, it was applied on all parcels and provided atmospheric deposits and concentrations of chlorpyrifos either in the gaseous and liquid aerosol phase at a 3-hourly interval. The phase of the substance was assumed not to evolve after emission and considered as a passive tracker.

\subsubsection{Multimedia exposure model}

Multimedia exposure modeling follows a mass balance approach and is based on the resolution of differential equations with first-rate kinetics. The modeling has been performed with two multimedia models, dynamiCROP [31, 32] for the assessment of environmental transfers, and Modul'ERS [33] to predict chlorpyrifos daily exposure doses from environmental compartments (water, air, soil and food).

Contamination of local food products cultivated in vegetable gardens was predicted from atmospheric deposits on plant and root uptake from soil. Four crops corresponding to the main 
food products consumed [36] were studied: apple, lettuce, potato and tomato. For each crop, one plant model was used to integrate transfer specificities (leaf, fruit, root, tuber). Transfers between plant, air and soil were predicted from the dynamiCROP model which was conveyed

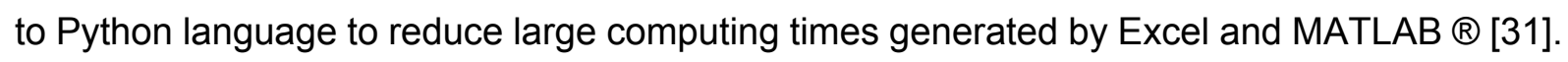
Chlorpyrifos concentrations were predicted at harvest time. Lettuce being a crop harvested all year round, all concentrations predicted each week of the year were weighted according to a probability of harvesting based on the evolution of the leaf area index (LAI).

One model was provided for each crop studied (apple, lettuce, potato, tomato) according to their specificities. In each model, plant biomass and LAI were the main time-varying parameters. The calculation method of these parameters was redefined from the initial model. They were weekly estimated to consider temporal variations. The calculation method of all other parameters directly depending on plant biomass and LAI, i.e., plant compartment biomasses, volumes and areas, part of the deposits reaching compartments, transfer coefficients and flow rates, was thus temporally adjusted. Finally, chlorpyrifos concentrations were computed using time-varied biomass values and transfer coefficients.

A percentage of self-consumption was defined from INSEE data [36]. It corresponds to the proportion of home-grown food products consumed (i.e. apple, lettuce, potato and tomato) in total food consumption per person. Four categories were defined, based on the number of inhabitants per urban unit (1) commune with less than 2,000 inhabitants (rural areas) (2) between 2,000 and 10,000 (3) between 10,000 and 100,000 (4) with more than 100,000 (Fig. S1).

Consumption of commercial food products was predicted using concentrations measurements from French and European studies (Table S3) and mean dietary beverage products consumption from the SISE-Eaux database [30]. 
Aggregated multimedia exposure was then assessed from ingestion and inhalation pathways. Inhalation pathway was given as the sum of chlorpyrifos concentrations $\left(C_{i n h}, \mathrm{mg}^{-3} \mathrm{~m}^{-3}\right)$ in its liquid $\left(C_{p a r}\right)$ and gaseous $\left(C_{\text {gas }}\right)$ phase:

$$
C_{i n h}=C_{\text {par }}+C_{\text {gas }}
$$

Ingestion pathway was predicted considering weight, quantities of food products ingested, water consumption [30], soil ingestion [37] and a self-consumption factor characterizing local food products ingestion. Intake from food products, water and soil, i.e. daily ingested doses $\left(D_{\text {ing }}, \mathrm{mg} . \mathrm{kg} \mathrm{bw}^{-1} \cdot \mathrm{d}^{-1}\right)$ were given from Eq. 2:

$$
D_{\text {ing }}=I_{\text {com }, \text { food }}+I_{\text {veg }}+I_{\text {soil }}+I_{H 2 O}
$$

where $I_{\text {com,food, }}, I_{\text {veg }}, I_{\text {soil }}$ and $I_{H 2 O}$ are intakes from commercial food products, local and commercial vegetables, soil and water.

\subsubsection{Toxicokinetic modeling and internal exposure}

To model the pharmacokinetics behavior of chlorpyrifos and its two metabolites: chlorpyrifosoxon (O,O-diethyl O-3,5,6-trichloro-2-pyridyl; CPF-oxon) and trichloropyridinol (3,5,6-trichloro2-pyridinol; TCPy), we used a PBPK/PD model developed by Poet et al. [38]. The model structure includes 10 tissue compartments for chlorpyrifos, 6 for chlorpyrifos-oxon and one urinary compartment for TCPy. This model considers changes in physiology, metabolism and sensitivity to toxicity over life-stages from childhood to adulthood and multi-route exposure [38]. It includes also physiological and metabolic changes that occur with pregnancy (increase in cardiac output, blood volume, fat mass). Three compartments (uterus, placenta, fetus) and their respective diffusion coefficients are included to describe the pregnancy [38]. The PBPK/PD model simulates the organ and blood concentrations of chlorpyrifos and chlorpyrifosoxon as well as the urinary excretion of TCPy. The model, initially built with acsIXtreme (Aegis Technologies), was converted to C-based GNU software MCSim [39]. 
In order to construct the exposure maps from spatialized databases, several statistical methods were used to specifically address environmental, behavioral or populational databases to increase their representativeness regarding the objectives of the exposure characterization. Data processing methods were adapted from the GIS-based modeling platform PLAINE ("Environmental INequalities Analysis PLatform") [40]. Statistical and geoprocessing methods interfaced in a GIS were particularly used to bypass the issues generated by data gaps and predict exposure indicators on the areas of interest.

Since air inputs were the main environmental spatial determinant considered in the modeling, a geostatistical analysis was conducted on atmospheric concentrations and deposits to assess spatial autocorrelations. This analysis was conducted in order to better define a relevant grid spatial resolution for reducing computation time and investigate the possibility to predict exposure at a specific point (i.e. a located address of a cohort participant to compare with measured biomarker) from initial grid calculation. This analysis consisted of studying the sample 2D-variogram and testing the anisotropy [41]. The variogram computed the dissimilarities between two-point values according to the distance between the points. Anisotropy was tested to verify whether spatial variability trends of the phenomena changed as a function of the direction [42]. These analyzes were carried out with $\mathrm{R}$ software and the package "RGeostats" (https://rgeostats.free.fr).

\section{Results} presence

277 Most of the applications occurred between the tenth and the nineteenth week of the year, i.e. 278 from mid-March to mid-May. The peak of applications was observed during April, between the 
279 thirteenth and the sixteenth week of the year. At this time, the mean amount of chlorpyrifos applied by parcel exceeded $50 \mathrm{~kg}$, or $5.7 \mathrm{~kg} / \mathrm{ha}$ (Fig. 2).

Following an application, air drifts occurred in a short time and were concentrated over a 36hour period. Volatilization rates, whether from soil or plant, extended over a longer period and behaved on the same way. $95 \%$ of volatilization rates were concentrated over a 3-week period (Fig. S2). The temporal evolutions of chlorpyrifos concentrations predicted in several environmental matrices such as air and lettuce were similar to those of volatilization rates (Fig. S3). For these two matrices, only $1 \%$ of initial concentrations remained after one month. However, concentration decrease in soil was slower to the point that there was still a third of chlorpyrifos after one month. It took about three months to drop below $5 \%$ of initial concentrations (Fig. S3).

\subsection{Chlorpyrifos presence in environmental media and its spatialization}

\subsubsection{Atmospheric concentrations and deposits}

The annual mean of predicted air concentrations varied from 0 to $5.5 \times 10^{-5} \mathrm{mg} / \mathrm{m}^{3}$ for the whole region. The spatial distribution of concentrations was rather homogeneous over Picardy. The main hotspots were located in the north-west of the region between Amiens and Abbeville, but also in the southwest of Beauvais, south of Soissons and around Laon (Fig. S4A). Monthly mean air concentrations during April varied from 0 to $7 \times 10^{-4} \mathrm{mg} / \mathrm{m}^{3}$ over the Picardy region and were up to 13 times higher than annual mean concentrations. Spatial distribution of air concentrations in April was broadly the same as for the annual mean concentrations (Fig. S4B). During the year, total atmospheric deposits per grid cell varied from 0 to $65 \mathrm{mg} / \mathrm{year}$ in Picardy. Spatial distribution of deposits was fairly homogeneous over Picardy. Main hotspots were located in the north-west of the region between Abbeville and Amiens as well as in the southeast (Fig. S4C). In April, atmospheric deposits represented on average $75 \%$ of the annual totals and rose up to $100 \%$ in some areas (Fig. S4D). 
The spatial distribution of atmospheric concentrations and deposits both displayed the same spatial structure and an anisotropy axis oriented from west southwest to east-northeast with a 65-degree angle to the North (Fig. S5). For both concentrations and deposits, the orthogonal variograms displayed a little anisotropy since the anisotropy ratios, for the minor axis, were 0.819 for concentrations and 0.843 for depositions. Additionally, ranges (i.e. distances where the model flattens out and where the autocorrelation between sample locations becomes negligible) were also close, i.e. $66 \mathrm{~km}$ for the major axis and $55 \mathrm{~km}$ for the minor axis (Fig. S6A and $\mathrm{B})$.

\subsubsection{Local food products}

Local food products, i.e. vegetable gardens in the vicinity of crop fields, are indirectly contaminated with chlorpyrifos deposits. Predicted concentrations in local-produced apples, potatoes and tomatoes were comprised, for $95 \%$ of them, between $9.4 \times 10^{-12}$ and $9.1 \times 10^{-8}$ $\mathrm{mg} / \mathrm{kg}$ of fresh weight for apples, $2.4 \times 10^{-11}$ and $2.3 \times 10^{-7} \mathrm{mg} / \mathrm{kg}$ of fresh weight for potatoes, $7.5 \times 10^{-11}$ and $6.9 \times 10^{-7} \mathrm{mg} / \mathrm{kg}$ of fresh weight for tomatoes respectively. Local food concentration predictions were less dispersed and rather centered around the median of the two concentration scenarios based on commercial food products measured (Fig. S7). For local-produced lettuces however, predictions were more centered around the maximum value measured in commercial lettuces, which peaked at $1.1 \times 10^{-2} \mathrm{mg} / \mathrm{kg}$ of fresh weight. Even $13 \%$ of predictions exceeded this maximum measured value. This singularity trend came from the cultivation of lettuce, which can be harvested throughout the year, while other crops are harvested several months after the end of spreading.

\subsection{Chlorpyrifos external exposure}

Annual mean daily inhalation doses for pregnant women varied between 0 and $9.1 \times 10^{-6}$ $\mathrm{mg} / \mathrm{kg} / \mathrm{d}$. The mean daily inhalation dose map clearly brought out rural areas with some hotspots distributed all over Picardy. Urban areas (categories 3 and 4, Fig. S1) showed low to medium inhalation doses, but the lowest doses were located in non-agricultural areas such as 
forests and tidal marshes. Spatial variability was high, extending over 10 orders of magnitude (Fig. 3A). Average daily inhalation doses during April varied between 0 and $1.2 \times 10^{-4} \mathrm{mg} / \mathrm{kg} / \mathrm{d}$ and exceeded the annual doses by a ten-fold factor. However, the April daily inhalation doses map presented the same spatial variability trend, i.e. hotspots in rural areas and lowest doses in forests and tidal marshes, as the annual map (Fig. 3B).

Annual mean daily ingestion dose maps for the lower bound scenario varied by a hundred-fold factor, between $1.6 \times 10^{-7}$ and $4.5 \times 10^{-5} \mathrm{mg} / \mathrm{kg} / \mathrm{d}$. There was no major difference-only $1.5 \%$ for the lower bound hypothesis-between annual mean and April mean ingestion doses. As for the inhalation, the lower bound scenario maps of daily exposure doses (Fig. 3C and D) brought out rural areas with hotspots in northern and southeastern Picardy. In the upper bound case, annual mean daily ingestion doses displayed a small variability across the entire area as the range between the minimal and maximal values, respectively $2.9 \times 10^{-4}$ and $3.4 \times 10^{-4} \mathrm{mg} / \mathrm{kg} / \mathrm{d}$, varied by $15 \%$. There was no difference between annual mean and April mean ingestion doses. The hotspots observed in the lower bound scenario maps were also observed in the upper bound scenario maps although both were globally more homogeneous (Fig. 3E and F).

\subsection{Environmental inequality characterization}

Annual mean TCPy urinary concentrations for pregnant women, resulting from the aggregation of inhalation and ingestion pathways, were comprised between $1.9 \times 10^{-6}$ and $6.6 \times 10^{-4} \mathrm{mg} / \mathrm{L}$, i.e. a 3-hundred factor, in the lower bound scenario. For the April predictions, the range of values extended by a thousand-fold factor, between $2.3 \times 10^{-6}$ and $2.5 \times 10^{-3} \mathrm{mg} / \mathrm{L}$. We observed a significant difference of values between the entire year and April. Indeed, April predictions were three to four times higher than annual predictions for the lower bound scenario (Fig. 4A and B). With the upper bound scenario, the range of TCPy urinary concentrations varied by $18 \%$ for the annual mean and were comprised between $3.6 \times 10^{-3}$ and $4.2 \times 10^{-3} \mathrm{mg} / \mathrm{L}$. For April, the range of predictions varied by $60 \%$, with concentrations comprised between $4.2 \times 10^{-3}$ and $6.6 \times 10^{-3} \mathrm{mg} / \mathrm{L}$. April predictions exceeded by $19 \%$ the annual predictions (Fig. 4C and D). 
The temporal evolution of TCPy urinary concentrations for pregnant women at the end of their first trimester were commonly at a steady state but strongly varied during the spreading period (Fig. S8). For the lower bound scenario, urinary TCPy concentrations began to increase in March and reached a maximum in April (about $90 \%$ of the maximum urinary TCPy concentrations). Then, the urinary TCPy concentrations decreased within six weeks and returned to steady state (about $20 \%$ of the maximum urinary TCPy concentrations).

The analysis of pathways contributions to TCPy urinary concentrations showed that ingestion was the prominent exposure pathway for both scenarios. It counted for $85 \%$ of overall exposure in the lower bound scenario and reached $99,5 \%$ in the upper bound scenario (Fig. 5). For this pathway, contributions of local food and commercial food also differed significantly between scenarios. While local food was the only contributor to the ingestion route in the lower bound scenario, commercial food largely dominated in the upper bound scenario (accounting for $99,2 \%$ of total exposure against $0,3 \%$ for local food). These observations only concerned annual mean. Inhalation contribution fluctuated monthly and became substantial during months where spreading was the highest. While inhalation contributed to 38 and $45 \%$ of overall exposure in March and May, it became the major pathway in April (83\%) when considering lower bound case. Commercial food still dominated in the upper bound scenario even if inhalation contribution reached $4 \%$ in April.

\section{Discussion}

In this study, we performed an integrated and spatialized exposure assessment approach applied for a pesticide at a regional scale. The coupling of models and the integration of environmental data in a GIS environment provides a detailed mapping of chlorpyrifos exposure. These maps provide insights for the identification of potentially more exposed areas and populations. The cartography of TCPy urinary concentrations in the lower bound scenario clearly highlights agricultural areas. In these maps, some specific areas and hotspots appear 
as potentially more exposed specifically in application period. For both scenarios, the different dietary behaviors between rural and urban areas reflect higher chlorpyrifos levels among the rural areas. These results are consistent with previous biomonitoring studies which have also found higher levels of urinary metabolite concentrations in rural populations than in urban populations or the general population [8, 43-45].

The comparison between internal dose predictions and measurements from biomonitoring studies allows to appreciate the quality of predicted values. Predictions were compared with data from North American cohorts measured over similar periods but not with French campaigns such as ELFE or ENNS because the TCPy was not retained in these studies [17, 18]. Moreover, a regional cohort, "MecoExpo", was constituted to estimate prenatal exposure but the analyzes did not allow to find traces of chlorpyrifos or its metabolites. Comparisons of TCPy urinary concentrations predictions with biomonitoring campaigns are shown in Table 1. Overall, the distribution of predictions lies in the range of the distributions of the measurements regardless of the period of the year. However, biomarker measurements consider all sources and exposure pathways at the individual level. Combined with questionnaires providing information on lifestyle habits, biomarker measurements and predictions of modeled internal concentrations allow to provide environmental contributions to distinguish behavioral and professional factors in the context of explanatory analyzes of impregnation.

In this study, we considered that TCPy urinary concentrations were only due to the metabolization of chlorpyrifos in human body. However, populations are directly exposed to chlorpyrifos-oxon and TCPy in the environment [48]. The presence of chlorpyrifos-oxon and TCPy in the environment could occur from the degradation of chlorpyrifos by biotic (microorganisms) and abiotic (photolysis, hydrolysis) processes [13]. It is then necessary to improve the consideration of degradation phenomena of chlorpyrifos in the environment especially as degradation is the main factor explaining mass evolution of pesticides [31].

Concerning the contributions to TCPy urinary levels, ingestion of commercial food is the most contributive pathway for the upper bound scenario. This finding is consistent with previous 
studies which found ingestion as the prominent residential exposure pathway [49, 50]. However, many uncertainties emerge from commercial food products data. Indeed, there are a high number of concentrations below detection and quantification limits within food databases. This led to a dual scenarization (lower and upper bound) of the exposure assessment which probably gives extreme estimates. In view of this, the integration of additional data, measured or modeled, would improve exposure predictions. Also, several statistical methods would allow to process data for which the majority of samples are below the limits of detection and quantification $[51,52]$. Moreover, probabilistic approaches such as Monte Carlo methods could propagate uncertainties over the entire computation chain. If we consider that ingestion of commercial food products contributes to more than $99 \%$ of aggregated exposure in the upper bound scenario, the influence of the atmospheric part is therefore marginal. Conversely, the lower bound scenario does not consider the ingestion of commercial food products and we only observe the contribution of the atmospheric part, i.e. ingestion of local food products and inhalation. Actual chlorpyrifos exposure probably lies between the two scenarios.

Exposure to chlorpyrifos can also result from exposure to other environmental media such as indoor air or home dust [49]. Our predictions do not consider indoor exposures derived from a former or current domestic use or medium contamination by outdoor sources. This source is potentially non-negligible as chlorpyrifos can stay many months after use [14]. In the same way, dermal pathway was not considered because it does not contribute significantly to overall exposure $[53,54]$, especially since dermal absorption is less than $3 \%[55,56]$. However, it could be incorporated into residential exposure assessment if contamination of indoor environments is considered as a source of exposure. It could also become a non-negligible exposure pathway in the case of agricultural workers using pesticides.

To improve this approach and regarding the computation time, it is necessary to address the relevance of the spatial and temporal resolutions of analysis to obtain the best compromise between predictions and computation times. In our study, seasonality of spreading plays a 
major role in the variability of exposure and contamination of environmental media over time, unlike diet whose contribution to overall exposure remains the same throughout the year. Following spreading, chlorpyrifos persists a few weeks to a few months in environmental media. In our study we demonstrated that the variation in TCPy urinary concentrations was greater during the three months of spreading. For both environmental media and humans, chlorpyrifos levels do not return to their previous state until one month after spreading. This analysis shows that it would be better to use a variable temporal resolution, focusing most of the predictions during the exposure window between mid-March and mid-June. Additionally, we chose a regular geographic grid cell to assess populational exposure regardless of their remoteness to agricultural areas. To obtain a grid resolution more representative of populational exposure at an individual level, we used geostatistical methods and the variogram analysis of chlorpyrifos atmospheric concentrations and deposition. This additional analysis makes it possible to apprehend spatial autocorrelation structures of these phenomena. From the analysis of the variogram models, we could define optimized spatial entities able to capture relevant individual and aggregated environmental and population information.

\section{Conclusion}

This study demonstrated the feasibility of an integrated approach for the evaluation of exposure to chlorpyrifos across the Picardy region. The use of this approach and the choice of fine spatio-temporal resolutions would allow researchers to improve exposure assessment methods. Both measurement and modeling approaches allow to assess the exposure of the populations considered with their own limits and uncertainties. The intersection of these complementary approaches improves the efficiency of decision-support tools to reduce the health and environmental impacts associated with exposure. Population stratification in the sampling plan based on exposure predictions can help reducing the number of samples in biomonitoring campaigns by selecting more contrasting individual profiles in terms of exposure. 
462 Likewise, predicting the evolution of biomarkers as a function of exposure makes it possible to 463 guide biomonitoring studies in order to identify key moments for sampling as well as to target 464 specific areas and moments in the year.

465 Beyond the uncertainties generated by data and models, the cartography of chlorpyrifos exposure helps decision-makers to identify potentially more exposed areas and populations and guide exposure reduction policies. To improve the approach, localized and regional biomonitoring campaigns should be conducted to compare them with exposure predictions. The analysis of spatio-temporal resolutions will also allow to extend the methodology on larger territories and other substances. Before that, a next step will be to refine this approach by integrating new datasets, other exposure pathways (indoor environments) and by using a probabilistic method based on Monte Carlo analysis. The representativeness of measurement data will also be improved by using advanced statistical methods to reconstruct censored data. The use of a probabilistic method will allow to consider uncertainties and to propagate them throughout the computing chain.

\section{Acknowledgements}

The authors would like to thank Dr. Peter Fantke from the Technical University of Denmark (DTU) for courteously providing them the dynamiCROP model. They would like to thank Dr. Torka S. Poet from Battelle Pacific Northwest Division for providing them the PBPK model of chlorpyrifos. They also would like to thank Christian Dersigny from Oise Agricultural Chamber

482 for providing spreading times for chlorpyrifos.

\section{Conflict of Interest}




\section{Funding}

486

487

488

489

490

491

492

493

494

495

496

497

498

499

500

501

502

503

504

505

506

507

508

This research was funded by the French minister in charge of the environment and by the French Biodiversity Agency (Agence française de la biodiversité - AFB) into the Ecophyto 2 plan context.

\section{References}

1. WHO. Environmental health inequalities in Europe. Second assessment report. WHO Regional Office for Europe: Copenhagen. 2019.

2. Wild CP. Complementing the genome with an "exposome": the outstanding challenge of environmental exposure measurement in molecular epidemiology. Cancer Epidemiol Biomarkers Prev. 2005;14:1847-50; doi:10.1158/1055-9965.EPI-05-0456.

3. Vrijheid M. The exposome: a new paradigm to study the impact of environment on health. Thorax. 2014;69:876-8; doi:10.1136/thoraxjnl-2013-204949.

4. Nuckols JR, Ward MH, Jarup L. Using Geographic Information Systems for Exposure Assessment in Environmental Epidemiology Studies. Environ Health Perspect. 2004;112:1007-15; doi:10.1289/ehp.6738.

5. Cui Y, Balshaw DM, Kwok RK, Thompson CL, Collman GW, Birnbaum LS. The Exposome: Embracing the Complexity for Discovery in Environmental Health. Environ Health Perspect. 2016;124 (8):A 137-140; doi:10.1289/EHP412.

6. Gavrilescu M. Fate of Pesticides in the Environment and its Bioremediation. Eng Life Sci. 2005;5;497-526; doi:10.1002/elsc.200520098.

7. Aubertot JN, Barbier JM, Carpentier A, Gril JN, Guichard L, Lucas P, et al. Pesticides, agriculture et Environnement: réduire l'Utilisation des pesticides et en limiter les impacts environnementaux. Quæ Editions: Versailles; 2005. French. 
509 8. Fenske RA, Lu C, Barr D, Needham L. Children's exposure to chlorpyrifos and parathion in an agricultural community in central Washington State. Environ Health Perspect. 2002;110:549-53; doi:10.1289/ehp.02110549.

9. Aschan-Leygonie C, Baudet-Michel S, Harpet C, Augendre M, Lavie E, Grésillon E, et al. Comment évaluer l'exposition aux pesticides de l'air en population générale ? Enseignements d'une revue bibliographique. Cybergeo. 2015;729; doi:10.4000/cybergeo.27056.

10. Fantke $\mathrm{P}$, Jolliet $\mathrm{O}$. Life cycle human health impacts of 875 pesticides. Int $\mathrm{J}$ Life Cycle Assess. 2016;21;722-33; doi:10.1007/s11367-015-0910-y.

11. Caudeville J. Caractérisation des inégalités environnementales : inventaire des bases de données nationales environnementales et spatialisées. Ineris: Verneuil-en-Halatte. INERIS-DRC-17-164533-00415B; 2017.

12. Dereumeaux C, Fillol C, Charles MA, Denys S. The French human biomonitoring program: First lessons from the perinatal component and future needs. Int $\mathrm{J}$ Hyg Environ Health. 2017;220:64-70; doi:10.1016/j.ijheh.2016.11.005.

13. John EM, Shaike JM. Chlorpyrifos: pollution and remediation. Environ Chem Lett. 2015;13:269-91; doi:10.1007/s10311-015-0513-7.

14. Eaton DL, Daroff RB, Autrup H, Bridges J, Buffler P, Costa LG, et al. Review of the Toxicology of Chlorpyrifos With an Emphasis on Human Exposure and Neurodevelopment. Crit Rev Toxicol. 2008;38 Suppl 2:1-125; doi:10.1080/10408440802272158.

15. Guo J, Zhang J, Wu C, Lv S, Lu D, Qi X, et al. Associations of prenatal and childhood chlorpyrifos exposure with Neurodevelopment of 3-year-old children. Environ Pollut. 2019;251:538-46; doi:10.1016/j.envpol.2019.05.040.

16. Rauh VA, Arunajadai S, Horton M, Perera F, Hoepner L, Barr DB, et al. Seven-Year Neurodevelopmental Scores and Prenatal Exposure to Chlorpyrifos, a Common Agricultural Pesticide. Environ Health Perspect. 2011;119:1196-201; doi:10.1289/ehp.1003160. 
17. Dereumeaux C, Saoudi A, Pecheux M, Berat B, de Crouy-Chanel P, Zaros C, et al. Biomarkers of exposure to environmental contaminants in French pregnant women from the Elfe cohort in 2011. Environ Int. 2016;97:56-67; doi:10.1016/j.envint.2016.10.013.

18. Fréry N, Saoudi A, Garnier R, Zeghnoun A, Falq G. Exposition de la population française aux substances chimiques de l'environnement. Institut de Veille sanitaire: Saint-Maurice. 2011. French.

19. Saint-Amand A, Willey J, Werry K, Faure S, Karthikeyan S, Lyonnais-Gagnon P, et al. Fifth Report on Human Biomonitoring of Environmental Chemicals in Canada. Health Canada: Ottawa. 2019.

20. NHANES. Fourth National Report on Human Exposure to Environmental Chemicals Volume 2. National Health And Nutrition Examination Survey: Atlanta, GA. 2019.

21. Schulz C, Angerer J, Ewers U, Heudorf U, Wilhelm M. Revised and new reference values for environmental pollutants in urine or blood of children in Germany derived from the German Environmental Survey on Children 2003-2006 (GerES IV). Int J Hyg Environ Health. 2009;212:637-47; doi:10.1016/j.ijheh.2009.05.003.

22. Béranger R, Hardy EM, Binter AC, Charles MA, Zaros C, Appenzeller BMR, et al. Multiple pesticides in mothers' hair samples and children's measurements at birth: Results from the French national birth cohort (ELFE). Int J Hyg Environ Health. 2020;223:22-33; doi:10.1016/j.ijheh.2019.10.010.

23. Jacquet F, Butault JP, Guichard L. An economic analysis of the possibility of reducing pesticides in French field crops. Ecol Econ. 2011;170:1638-48; doi:10.1016/j.ecolecon.2011.04.003.

24. E-Phy. Agence nationale de sécurité sanitaire de l'alimentation, de l'environnement et du travail. 2020. https://ephy.anses.fr/substance/chlorpyrifos. Accessed 4 May 2020.

25. National Bank of Plant Protection Products Sales by Authorized Distributors. 2020. http://www.data.eaufrance.fr/jdd/bd45f801-45f7-4f8c-b128-a1af3ea2aa3e. Accessed 4 May 2020. 
26. Desert M, Ravier S, Gille G, Quinapallo A, Armengaud A, Pochet G, et al. Spatial and temporal distribution of current-use pesticides in ambient air of Provence-Alpes-Côted'Azur Region and Corsica, France. Atmospheric Environ. 2018;192:241-56; doi:10.1016/j.atmosenv.2018.08.054.

27. Synop Essential WMO Database. Météo- France: Saint-Mandé. 2020. https://donneespubliques. meteofrance.fr/?fond=produit\&id produit=90\&id rubrique=32. Accessed 17 Jun 2020.

28. Leblanc JC, coordination, Sirot V, coordination, et al. Étude de l'alimentation totale française 2 (EAT 2) - Tome 2. Agence nationale de sécurité sanitaire de l'alimentation, de l'environnement et du travail: Maisons-Alfort. 2011. French.

29. EFSA. The 2013 European Union report on pesticide residues in food. EFSA Journal. 2015;13 (3):4038; doi:10.2903/j.efsa.2015.4038.

30. Davezac H, Grandguillot G, Robin A, Saoult C. L'eau potable en France 2005-2006. French Ministry for Health, Youth and Sports: Paris. 2008. French.

31. Fantke P, Charles R, de Alencastro LF, Friedrich R, Jolliet O. Plant uptake of pesticides and human health: Dynamic modeling of residues in wheat and ingestion intake. Chemosphere. 2011a;85:1639-47; doi:10.1016/j.chemosphere.2011.08.030.

32. Fantke $P$, Juraske $R$, Antón $A$, Friedrich $R$, Jolliet $O$. Dynamic Multicrop Model to Characterize Impacts of Pesticides in Food. Environ Sci Technol. 2011b;45:8842-9; doi:10.1021/es201989d.

33. Bonnard R. Jeux d'équations pour la modélisation des expositions liées à la contamination d'un sol ou aux émissions d'une installation industrielle. Ineris : Verneuil-en-Halatte. DRC08-94882-16675C; 2010. French.

34. Dijkman TJ, Birkved M, Hauschild MZ. PestLCl 2.0: a second generation model for estimating emissions of pesticides from arable land in LCA. Int $\mathrm{J}$ Life Cycle Assess. 2012;17:973-986; doi:10.1007/s11367-012-0439-2.

35. Arnold AC. A Comparative Study of Drop Sizing Equipment for Agricultural Fan-Spray Atomizers. Aerosol Sci Technol. 1990;12:431-45; doi:10.1080/02786829008959358. 
36. Bertrand M. Consommation et lieux d'achat des produits alimentaires en 1991. INSEERésultats. 1993;262-3. French.

37. Bonnard R. Paramètres d'exposition de l'Homme du logiciel MODUL'ERS. Ineris: Verneuilen-Halatte. DRC-14-141968-11173C; 2017. French.

38. Poet TS, Timchalk C, Bartels MJ, Smith JN, McDougal R, Juberg DR, et al. Use of a probabilistic PBPK/PD model to calculate Data Derived Extrapolation Factors for chlorpyrifos. Regul Toxicol Pharmacol. 2017;86:59-73; doi:10.1016/j.yrtph.2017.02.014.

39. Bois FY, Maszle DR. MCSim: A Monte Carlo Simulation Program. J Stat Softw. 1997;2 (9); doi:10.18637/jss.v002.i09.

40. Caudeville J, Bonnard R, Boudet C, Denys S, Govaert G, Cicolella A. Development of a spatial stochastic multimedia model to assess population exposure at a regional scale. Sci Total Environ. 2012;432:297-308, doi:10.1016/j.scitotenv.2012.06.001.

41. Gotway Crawford CA, Hergert GW. Incorporating Spatial Trends and Anisotropy in Geostatistical Mapping of Soil Properties. Soil Sci Soc Am J. 1997;61 (1):298-309; doi:10.2136/sssaj1997.03615995006100010043x.

42. Goovaerts P. Geostatistics for Natural Resources Evaluation. 1st ed. Oxford University Press: New York; 1997.

43. Deziel NC, Frisen MC, Hoppin JA, Hines CJ, Thomas K, Freeman LEB. A Review of Nonoccupational Pathways for Pesticide Exposure in Women Living in Agricultural Areas. Environ Health Perspect. 2015;123:515-24; doi:10.1289/ehp.1408273.

44. Alexander BH, Burns CJ, Bartels MJ, Acquavella JF, Mandel JS, Gustin C, et al. Chlorpyrifos exposure in farm families: results from the Farm Family Exposure Study. J Expo Sci Environ Epidemiol. 2006;16:447-53; doi:10.1038/sj.jes.7500475.

45. Curwin BD, Hein MJ, Sanderson WT, Striley C, Heederik D, Kromhout H, et al. Urinary pesticide concentrations among children, mothers and fathers living in farm and non-farm households in lowa. Ann Occup Hyg. 2007;51:53-65; doi:10.1093/annhyg/mel062. 
46. Arcury TA, Laurienti PJ, Talton JW, Chen H, Howard TD, Barr DB, et al. Pesticide Urinary Metabolites Among Latina Farmworkers and Non-Farmworkers in North Carolina. J Occup Environ Med. 2018;60 (1):e63-e71; doi:10.1097/JOM.0000000000001189.

47. Whyatt RM, Garfinkel R, Hoepner LA, Andrews H, Holmes D, Williams MK, et al. A Biomarker Validation Study of Prenatal Chlorpyrifos Exposure within an Inner-City Cohort during Pregnancy. Environ Health Perspect. 2009;117:559-67; doi:10.1289/ehp.0800041.

48. Egeghy PP, Cohen Hubal EA, Tulve NS, Melnyk LJ, Morgan MK, Fortmann RC, et al. Review of Pesticide Urinary Biomarker Measurements from Selected US EPA Children's Observational Exposure Studies. Int J Environ Res Public Health. 2011;8:1727-54; doi:10.3390/ijerph8051727.

49. Egeghy PP, Quackenboss JJ, Catlin S, Ryan PB. Determinants of temporal variability in NHEXAS-Maryland environmental concentrations, exposures, and biomarkers. J Expo Anal Environ Epidemiol. 2005;15:388-97; doi:10.1038/sj.jea.7500415.

50. Morgan MK, Sheldon LS, Croghan CW, Chuang JC, Lyu C, Wilson NK, et al. A Pilot Study of Children's Total Exposure to Persistent Pesticides and Other Persistent Organic Pollutants (CTEPP). U.S. Environmental Protection Agency: Washington, DC. 2004. EPA/600/R-041/193.

51. Beal SL. Ways to fit a PK model with some data below the quantification limit. J Pharmacokinet Pharmacodyn. 2001;28:481-504; doi:10.1023/A:1012299115260.

52. Hecht M, Veigure R, Couchman L, Barker CIS, Standing JF, Takkis K, et al. Utilization of data below the analytical limit of quantitation in pharmacokinetic analysis and modeling: promoting interdisciplinary debate. Bioanalysis. 2018;10:1229-48; doi:10.4155/bio-2018$\underline{0078}$.

53. Byrne SL, Shurdut BA, Saunders DG. Potential Chlorpyrifos Exposure to Residents Following Standard Crack and Crevice Treatment. Environ Health Perspect. 1998;106:725-31; doi:10.1289/ehp.98106725.

54. Zartarian V, Özkaynak H, Burke JM, Zufall MJ, Rigas ML, Furtaw Jr EJ. A Modeling Framework for Estimating Children's Residential Exposure and Dose to Chlorpyrifos Via 
645 Dermal Residue Contact and Nondietary Ingestion. Environ Health Perspect. $646 \quad$ 2000;108:505-13; doi:10.1289/ehp.00108505.

647 55. Nolan RJ, Rick DL, Freshour NL, Saunders JH. Chlorpyrifos: Pharmacokinetics in Human 648 Volunteers. Toxicol Appl Pharmacol. 1984;73:8-15; doi:10.1016/0041-008X(84)90046-2. 649 56. Meuling WJA, Ravensberg LC, Roza L, van Hemmen JJ. Dermal absorption of chlorpyrifos 650 in human volunteers. Int Arch Occup Environ Health. 2005;78:44-50; doi:10.1007/s00420$651 \quad$ 004-0558-6. 


\section{Figure legends}

654 Table 1 - Comparisons of TCPy urinary concentrations $(\mathrm{mg} / \mathrm{L})$ predicted with measurements from biomonitoring campaigns

655 Figure 1 - Conceptual scheme of the modeling approach used in this study. Environmental data (blue) are integrated into models (green) which

656 characterize the transfers of chlorpyrifos from the source to the contamination of the target populations. Output data generated by these models (white) are themselves integrated as input data of the following model. At the end of the modeling chain are predicted the external and internal

658 exposure doses (yellow).

659 Figure 2 - Seasonality of chlorpyrifos spreading in Picardy. Red symbols are the mean and the $95 \%$ confidence interval of the quantities applied

660 on each agricultural field. Note that the application period is very short and that the peak is reached during early spring.

661 Figure 3 - Mapping of daily exposure doses for the inhalation and ingestion pathways for pregnant women in Picardy. A) Mean annual daily inhalation

662 doses; B) Mean daily inhalation doses during April; C) Mean annual daily ingestion doses (lower bound); D) Mean daily ingestion doses during April

663 (lower bound); E) Mean daily ingestion doses (upper bound); F) Mean daily ingestion doses during April (upper bound). There is a seasonal difference

664 between annual and April mean inhalation doses but not for ingestion doses. For these, only the difference between the scenarios is notable.

Figure 4 - Mapping of urinary concentrations of TCPy for pregnant women in Picardy. A) Mean annual urinary concentrations (lower bound); B) Mean urinary concentrations during April (lower bound); C) Mean annual urinary concentrations (upper bound); D) Mean urinary concentrations during April (upper bound). These maps result from the aggregation of the ingestion and inhalation exposure pathways for each scenario. For the lower bound scenario, there is a difference in urinary concentrations between the year and April. This case is however not found in the upper bound

670 Figure 5 - Mean contributions of exposure pathways to aggregated TCPy urinary concentrations for the lower bound (A) and upper bound (B)

671 scenarios. For both scenarios, ingestion is the major exposure pathway.

\section{Tables}

\begin{tabular}{|c|c|c|c|c|c|c|c|c|}
\hline & Population & Period & P10 & P25 & $\begin{array}{l}\text { Percent } \\
\text { P50 }\end{array}$ & P75 & P90 & P95 \\
\hline $\begin{array}{l}\text { Lower } \\
\text { bound } \\
\text { (year) }\end{array}$ & & & $2.70 \mathrm{e}^{-3}$ & $5.40 \mathrm{e}^{-3}$ & $1.07 e^{-2}$ & $2.18 \mathrm{e}^{-2}$ & $4.25 \mathrm{e}^{-2}$ & $6.82 \mathrm{e}^{-2}$ \\
\hline $\begin{array}{l}\text { Lower } \\
\text { bound } \\
\text { (April) } \\
\text { Upper }\end{array}$ & $\begin{array}{l}\text { Pregnant } \\
\text { women }\end{array}$ & 2013 & $5.76 \mathrm{e}^{-3}$ & $1.86 \mathrm{e}^{-2}$ & $4.28 \mathrm{e}^{-2}$ & $9.23 \mathrm{e}^{-2}$ & 0.18 & 0.28 \\
\hline $\begin{array}{l}\text { bound } \\
\text { (year) } \\
\text { Upper }\end{array}$ & & & 3.56 & 3.56 & 3.57 & 3.58 & 3.60 & 3.63 \\
\hline $\begin{array}{l}\text { bound } \\
\text { (April) }\end{array}$ & & & 4.17 & 4.18 & 4.21 & 4.25 & 4.34 & 4.44 \\
\hline $\begin{array}{l}\text { Arcury et al. } \\
(2018) \text { [46] }\end{array}$ & $\begin{array}{c}\text { Non- } \\
\text { farmworkers } \\
\text { women } \\
\text { (Hispanic) }\end{array}$ & 2013 & - & 1.3 & 2.6 & 3.7 & 4.2 & - \\
\hline $\begin{array}{l}\text { NHANES } \\
(2019) \text { [20] }\end{array}$ & Women & $2009-2010$ & - & - & 0.34 & 1.88 & 3.22 & 4.40 \\
\hline $\begin{array}{c}\text { Health } \\
\text { Canada } \\
(2017)[19]\end{array}$ & $\begin{array}{l}\text { Women (3-79 } \\
\text { years) }\end{array}$ & $2014-2015$ & 0.31 & - & 1.10 & - & 5.20 & 7.80 \\
\hline $\begin{array}{l}\text { Whyatt et al. } \\
\text { (2009) [47] }\end{array}$ & $\begin{array}{l}\text { Pregnant } \\
\text { women (Afro- } \\
\text { American and } \\
\text { Dominican) }\end{array}$ & $2001-2004$ & $<0.26$ & $<0.26$ & $<0.26$ & 1.02 & 3.30 & 4.80 \\
\hline
\end{tabular}




\section{Supplemental materials}

\section{Spatio-temporal assessment of pregnant women exposure to chlorpyrifos at a regional scale}

Corentin Regrain, Florence Zeman, Mohammed Guedda, Karen Chardon, Véronique Bach, Céline Brochot, Roseline Bonnard, Frédéric Tognet, Laure Malherbe, Laurent Letinois, Emmanuelle Boulvert, Fabrice Marlière, François Lestremau, Julien Caudeville

\section{$\underline{\text { Table of contents }}$}

\section{Figures}

Figure S1 - Location of urban zones in Picardy according to the typology of INSEE (>2000 inhabitants).

Figure S2 - Cumulative frequencies of volatilization rates. Lines depict air drift (red), volatilization from plant (green) and from soil (blue). Quantities are ranked in descending order. Volatilization processes take place over short periods, i.e. less than a month. Air drift appears to be instantaneous compared to volatilization rates from soil and plant.

Figure S3 - Time evolution of chlorpyrifos concentrations in air (blue), soil (red) and lettuce (green) after an application. Chlorpyrifos concentrations decrease within four weeks in air and lettuce while this process takes several months for the soil.

Figure S4 - Maps of air concentrations and atmospheric deposits in Picardy. Maps A and B show the distribution of mean atmospheric concentrations in nanograms per cubic meter over the year $(A)$ and during April (B). Map $C$ shows the annual distribution of atmospheric deposits in milligrams while Map $D$ represents the percentage of deposits occurring in April. It is during April that the atmospheric concentrations are the most important and it is also the month that contributes the most to annual deposits.

Figure S5 - Variogram maps of air concentrations (A) and deposits (B). The variogram maps display an anisotropy axis oriented from west-southwest to east-northeast.

Figure S6 - Comparisons between air concentrations (A) and deposits (B) anisotropic variograms. Black lines depict major axis variograms and red lines depict minor axis variograms.

Figure S7 - Comparison between local food products concentration estimates at harvest and measurements from EFSA and EAT2 studies for the four crops. Red boxplots depict predicted concentrations of chlorpyrifos for each locally-produced crop. Green boxplots depict concentration ranges for each commercial crop according to the two scenarii (lower bound and upper bound). Values are expressed in $\mathrm{mg}$ per kilogram of fresh weight.

Figure S8 - Time evolution of TCPy urinary concentrations during the year for pregnant women at the end of their first trimester. Red line displays lower bound TCPy concentrations and green line displays upper bound concentrations. For both scenarii, the peak of urinary concentrations is comprised between March and May.

Figure S9 - Inhalation pathway contributions to overall TCPy concentrations. Comparisons between annual mean and monthly means for months which agricultural spreading are the highest.

\section{Tables}

Table S1 - Available data and use.

Table S2 - Quantification rates obtained from different food products in EAT2 and EFSA studies.

Table S3 - Concentration values used for commercial food products ( $\mathrm{mg} / \mathrm{kg}$ of fresh weight).

\section{References}




\section{Figures}

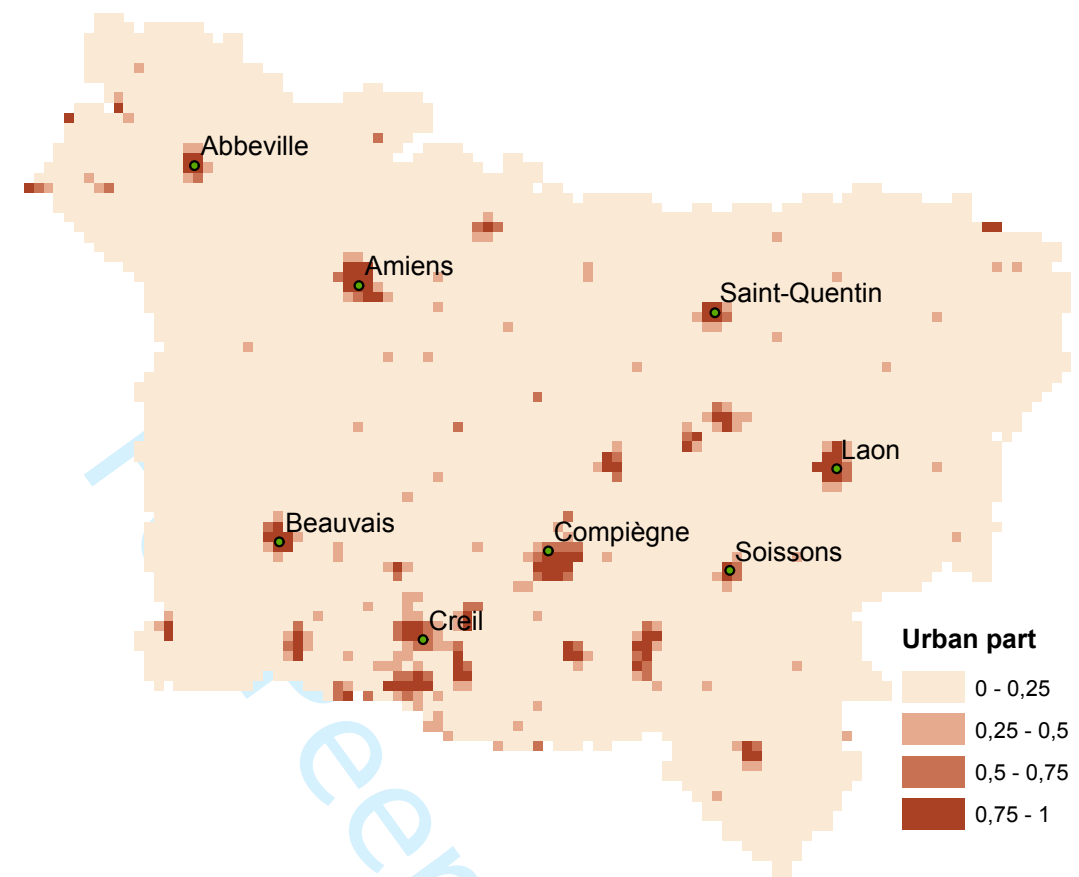

Figure S1 - Location of urban zones in Picardy according to the typology of INSEE (>2000 inhabitants).

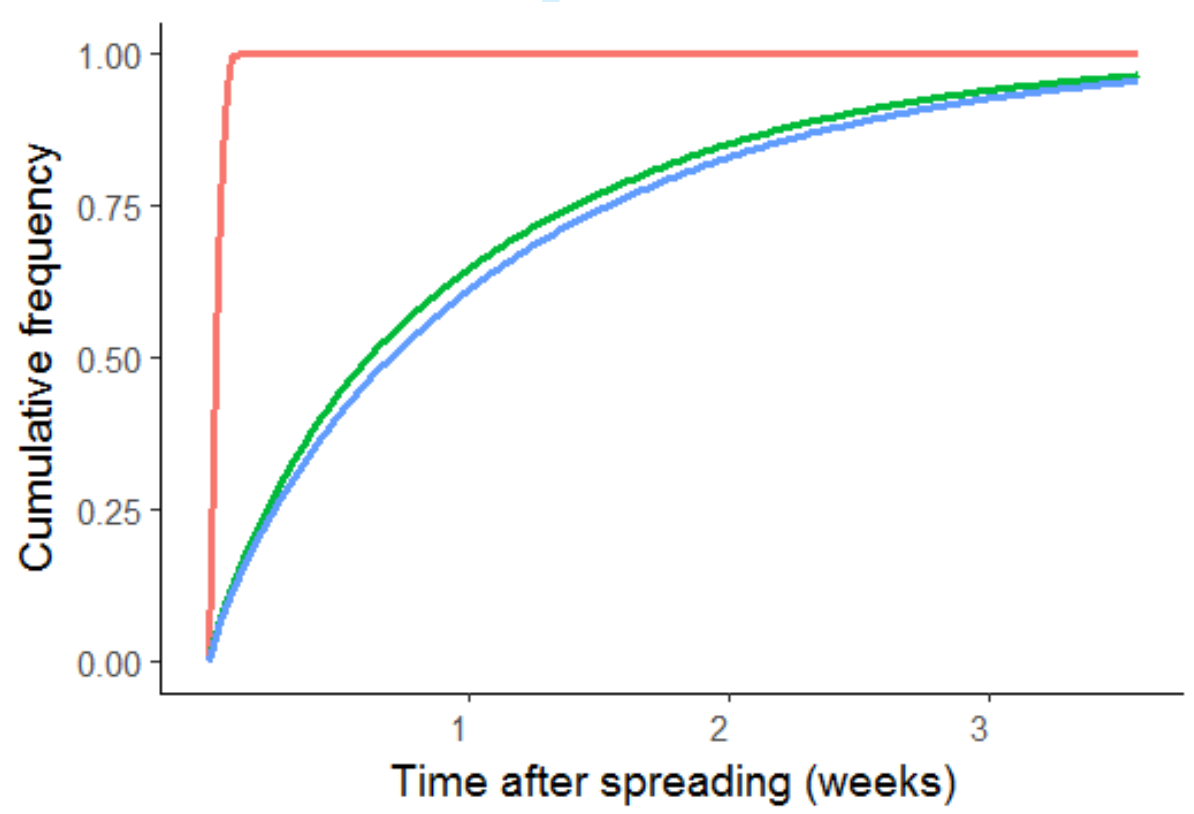

Figure S2 - Cumulative frequencies of volatilization rates. Lines depict air drift (red), volatilization from plant (green) and from soil (blue). Quantities are ranked in descending order. Volatilization processes take place over short periods, i.e. less than a month. Air drift appears to be instantaneous compared to volatilization rates from soil and plant. 


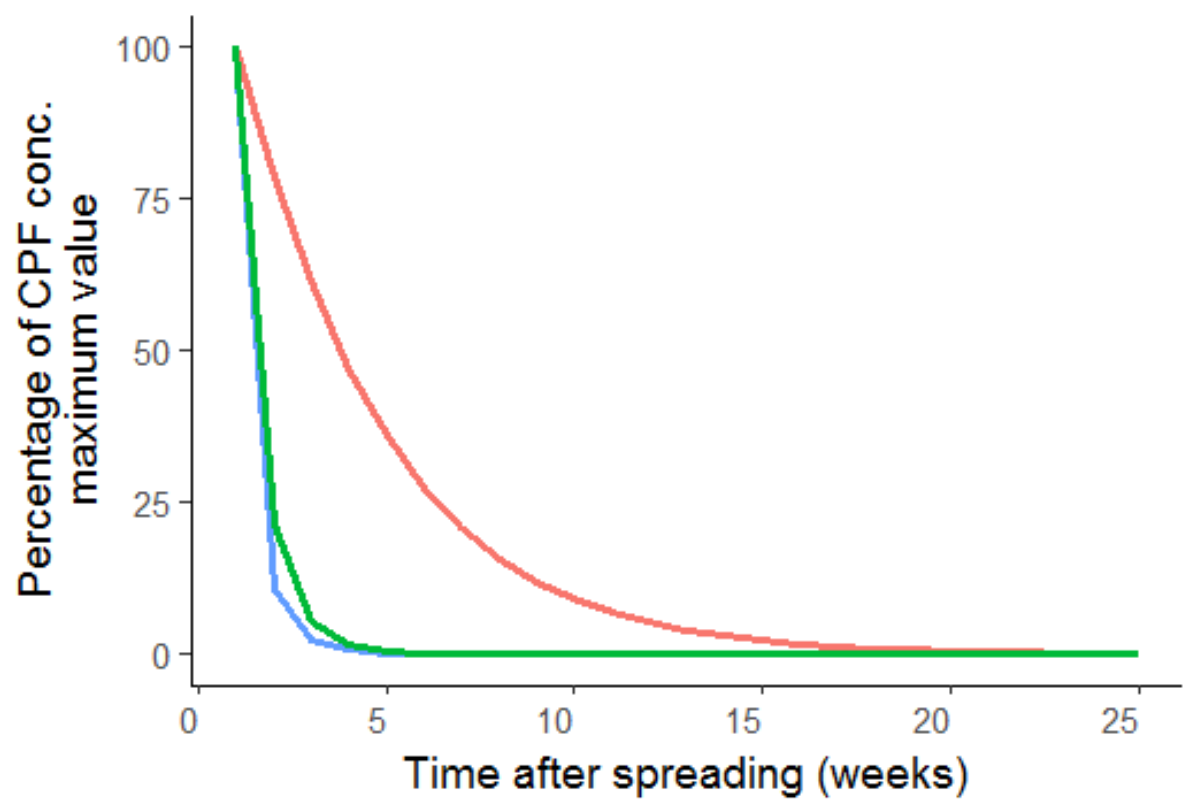

Figure S3 - Time evolution of chlorpyrifos concentrations in air (blue), soil (red) and lettuce (green) after an application. Chlorpyrifos concentrations decrease within four weeks in air and lettuce while this process takes several months for the soil.
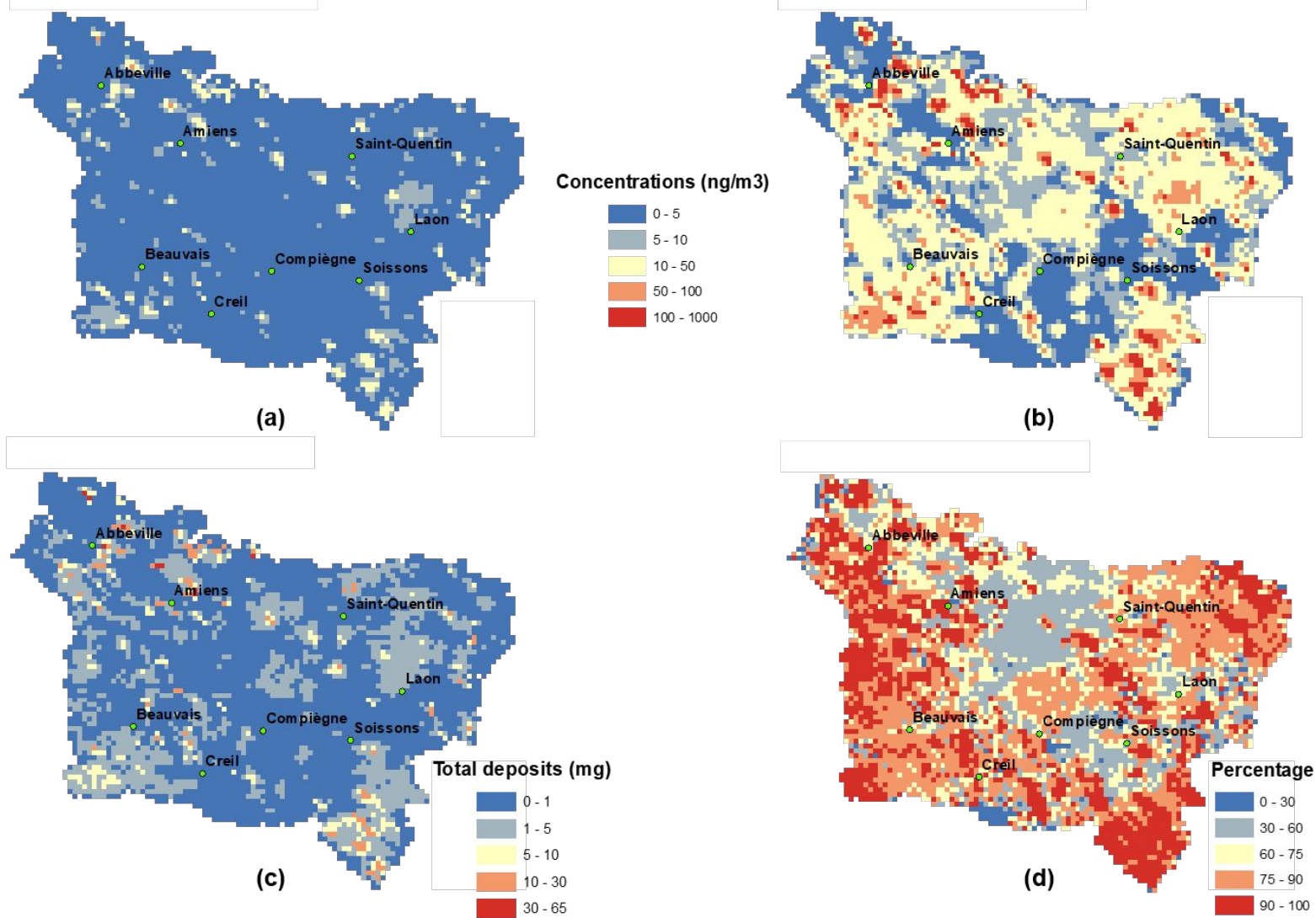

Figure S4 - Maps of air concentrations and atmospheric deposits in Picardy. Maps A and B show the distribution of mean atmospheric concentrations in nanograms per cubic meter over the year $(A)$ and during April (B). Map $C$ shows the annual distribution of atmospheric deposits in milligrams while Map $D$ represents the percentage of deposits occurring in April. It is during April that the atmospheric concentrations are the most important and it is also the month that contributes the most to annual deposits. 

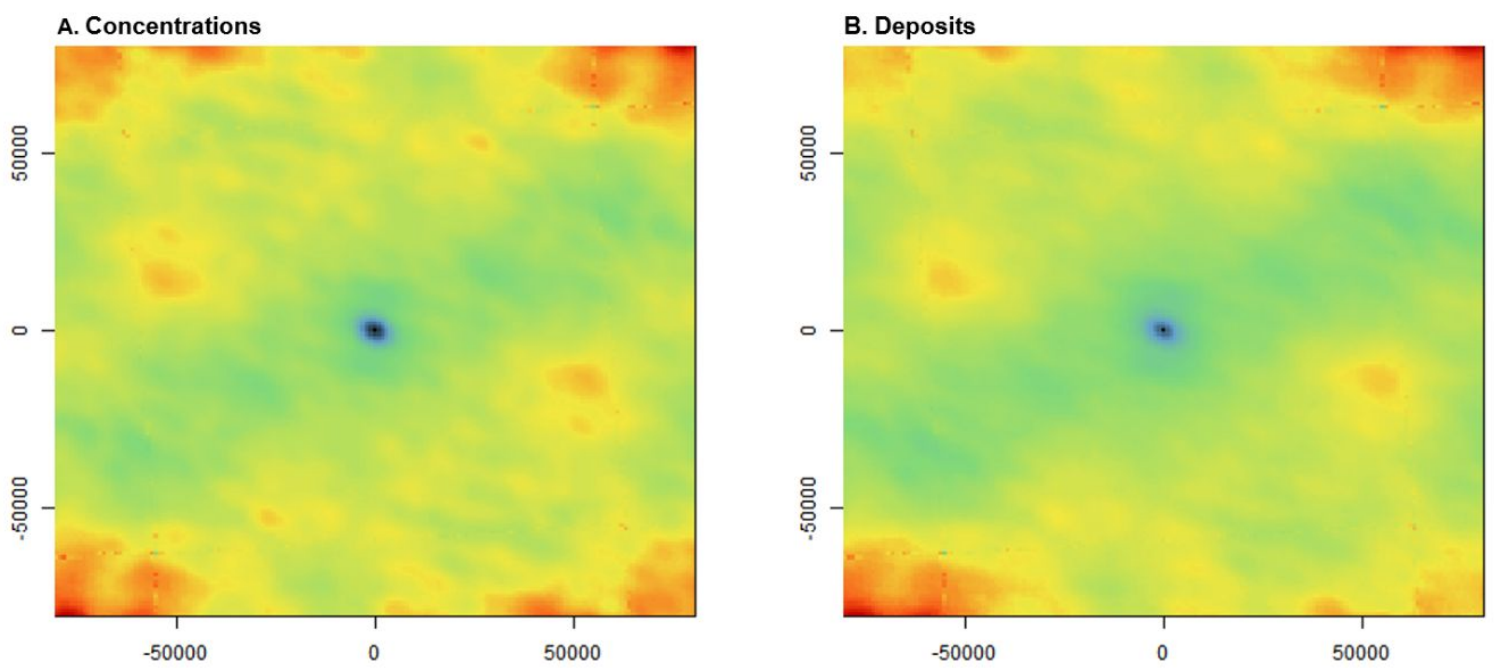

Figure S5 - Variogram maps of air concentrations (A) and deposits (B). The variogram maps display an anisotropy axis oriented from west-southwest to east-northeast.

A. Concentrations

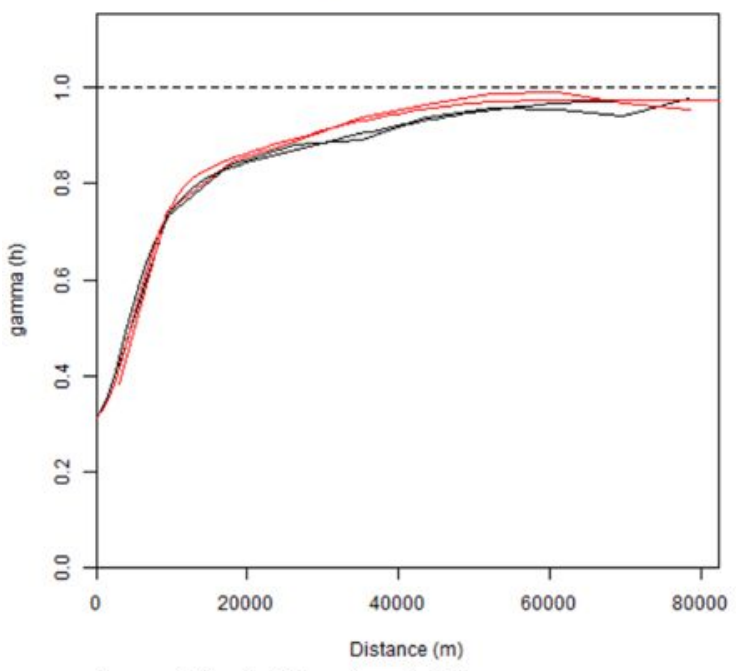

Ranges - Major axis: $68 \mathrm{~km}$; minor axis: $56 \mathrm{~km}$
B. Deposits

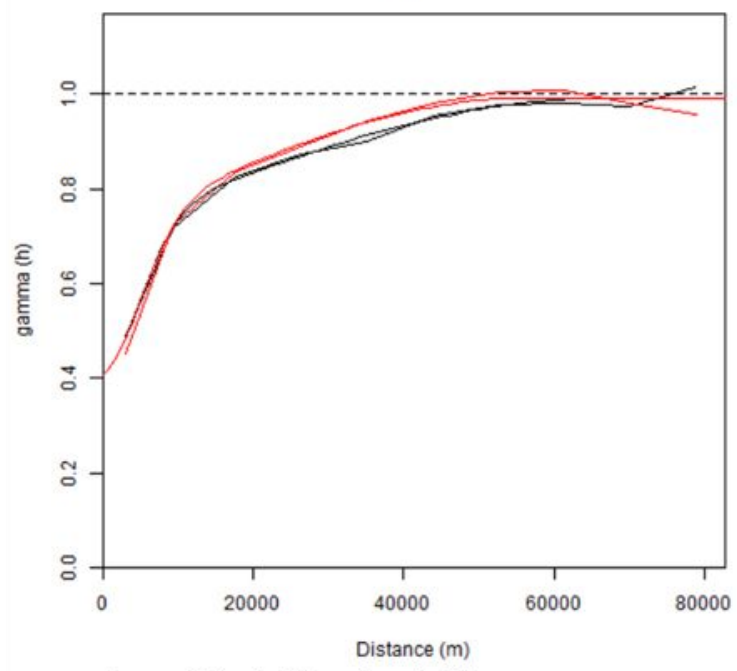

Ranges - Major axis: $66 \mathrm{~km}$; minor axis: $56 \mathrm{~km}$

Figure S6 - Comparisons between air concentrations (A) and deposits (B) anisotropic variograms. Black lines depict major axis variograms and red lines depict minor axis variograms. 


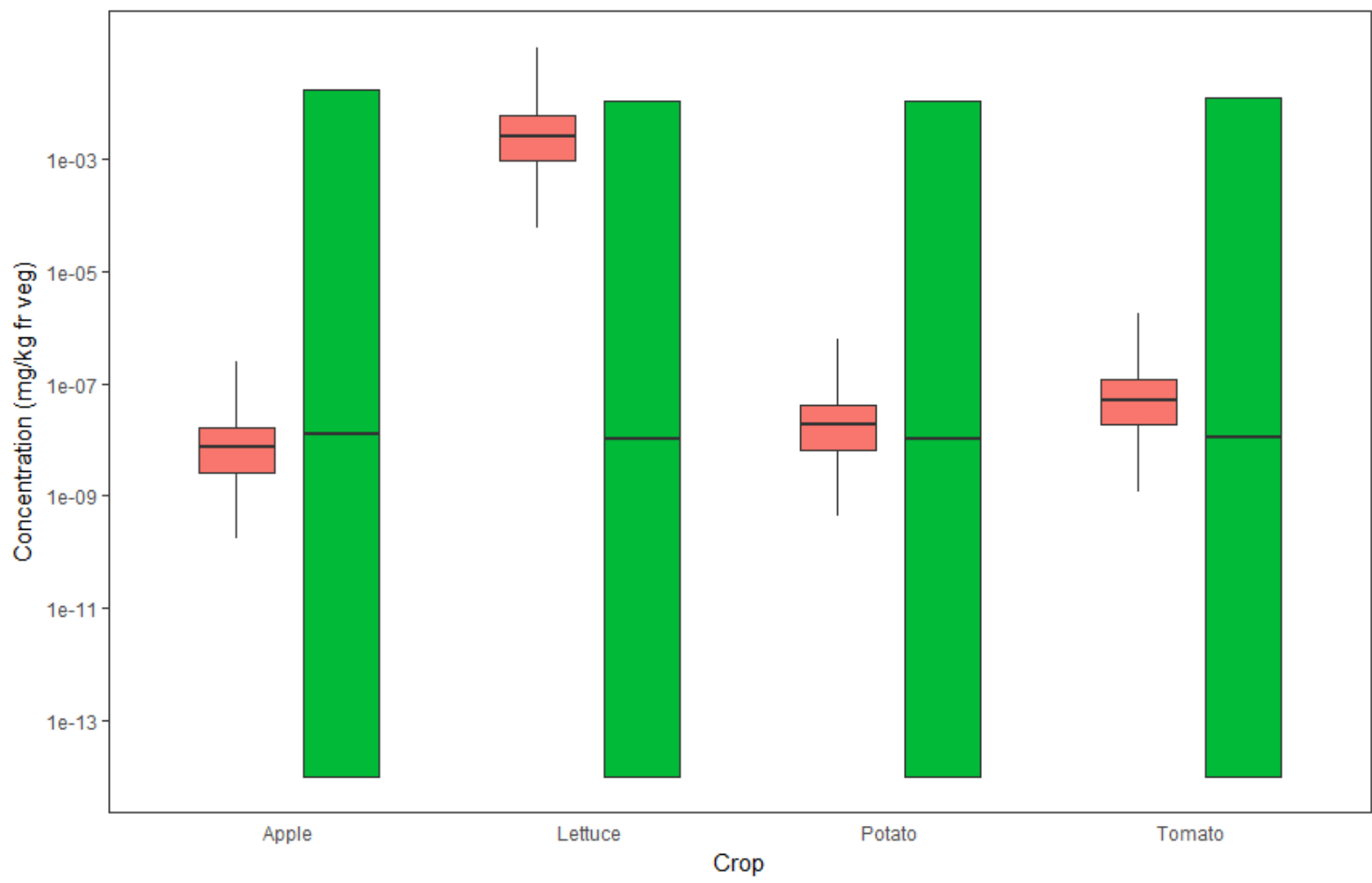

Figure S7 - Comparison between local food products concentration estimates at harvest and measurements from EFSA and EAT2 studies for the four crops. Red boxplots depict predicted concentrations of chlorpyrifos for each locally-produced crop. Green boxplots depict concentration ranges for each commercial crop according to the two scenarii (lower bound and upper bound). Values are expressed in mg per kilogram of fresh weight.

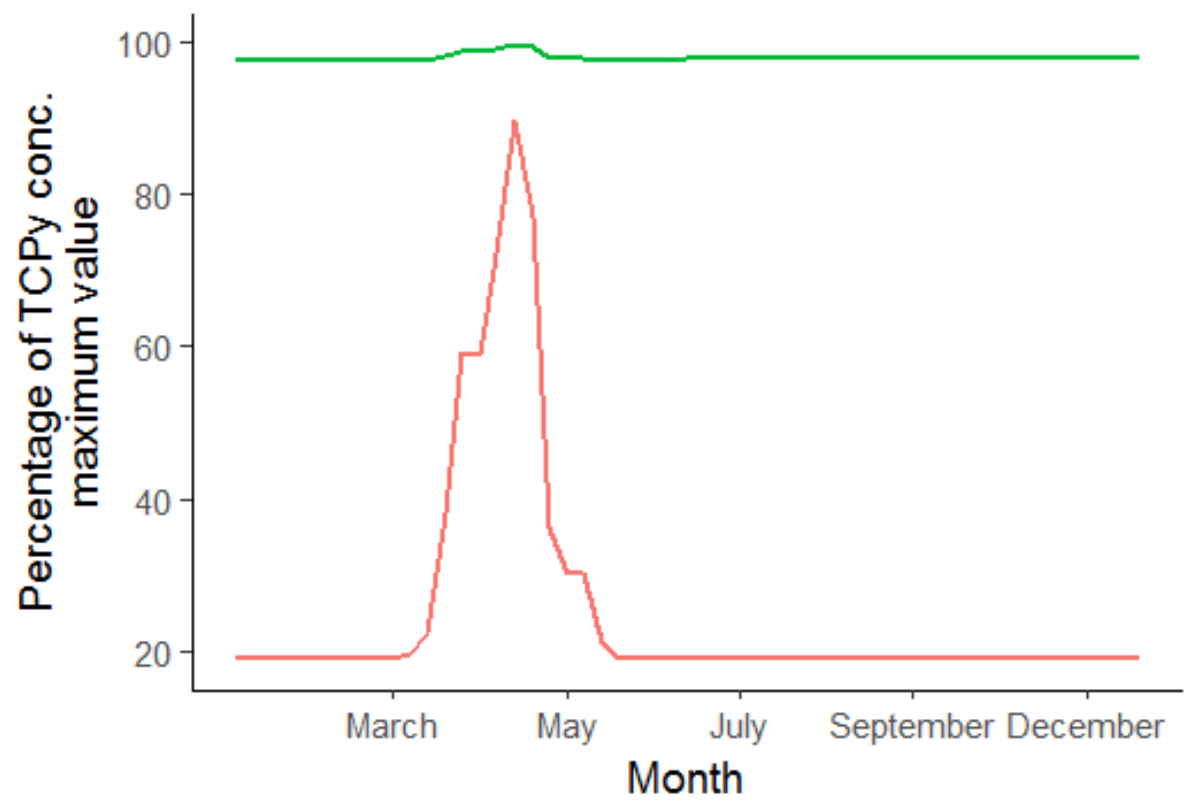

Figure S8 - Time evolution of TCPy urinary concentrations during the year for pregnant women at the end of their first trimester. Red line displays lower bound TCPy concentrations and green line displays upper bound concentrations. For both scenarii, the peak of urinary concentrations is comprised between March and May. 

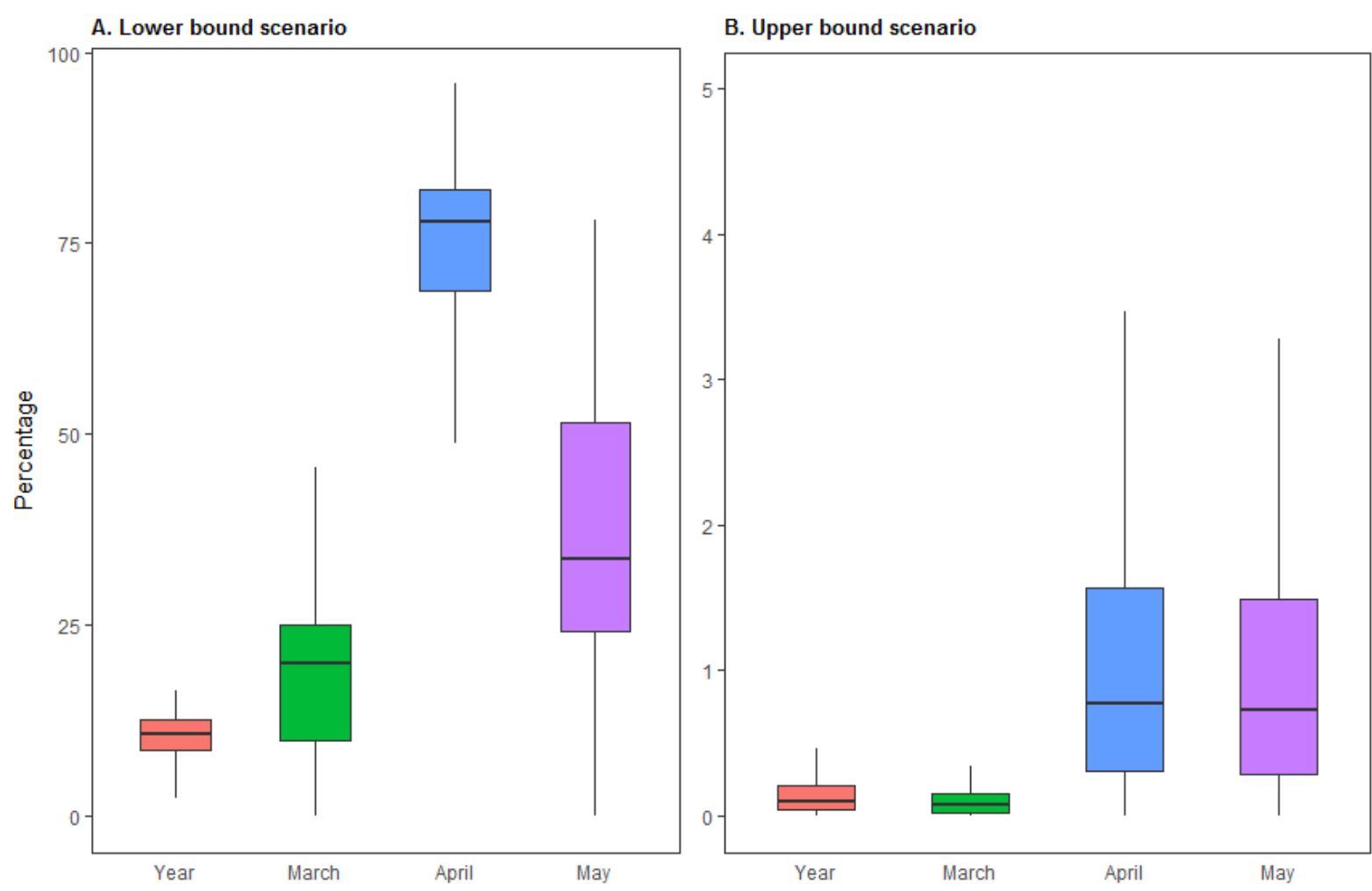

Figure S9 - Inhalation pathway contributions to overall TCPy concentrations. Comparisons between annual mean and monthly means for months which agricultural spreading are the highest.

\section{Tables}

Table S1 - Available data and use.

\begin{tabular}{|c|c|}
\hline Variable & Data source and use \\
\hline $\begin{array}{l}\text { Plant protection } \\
\text { product sales }\end{array}$ & $\begin{array}{l}\text { National Bank of Plant Protection Products } \\
\text { Sales by Authorized Distributors (BNV-D, 2020). } \\
\text { To be used to predict annual quantities applied. }\end{array}$ \\
\hline Spreading times & $\begin{array}{c}\text { Departmental agricultural chambers (Chambres } \\
\text { d'Agriculture Hauts-de-France, 2020). To be } \\
\text { used to predict annual quantities applied. }\end{array}$ \\
\hline $\begin{array}{c}\text { Wind } \\
\text { Temperature } \\
\text { Precipitations } \\
\text { Humidity } \\
\text { Cloudiness }\end{array}$ & $\begin{array}{c}\text { Synop Essential WMO (Synop Essentielles } \\
\text { OMM, 2020). To be used to predict atmospheric } \\
\text { dispersion. }\end{array}$ \\
\hline $\begin{array}{l}\text { Concentrations in } \\
\text { commercial food } \\
\text { products }\end{array}$ & $\begin{array}{l}\text { French Total Diet Study (Leblanc et al., 2011) } \\
\text { and EFSA (EFSA, 2015). To be used to predict } \\
\text { dietary ingestion exposure. }\end{array}$ \\
\hline $\begin{array}{l}\text { Concentrations in tap } \\
\text { water }\end{array}$ & $\begin{array}{l}\text { SISE-Eaux (Davezac et al., 2008). To be used } \\
\text { to predict water consumption exposure. }\end{array}$ \\
\hline
\end{tabular}

Table S2 - Quantification rates obtained from different food products in EAT2 and EFSA studies.

\begin{tabular}{cc}
\hline Study & $\begin{array}{c}\text { Quantification } \\
\text { rate }\end{array}$ \\
\hline EAT2 (France) & $1.1 \%$ \\
EFSA (EU) & $7.3 \%$ \\
\hline
\end{tabular}


Table S3 - Concentration values used for commercial food products ( $\mathrm{mg} / \mathrm{kg}$ of fresh weight).

\begin{tabular}{|c|c|c|c|c|}
\hline \multirow[t]{2}{*}{ Food product } & \multirow[t]{2}{*}{ LOD } & \multirow[t]{2}{*}{ LOQ } & \multicolumn{2}{|c|}{ Scenario } \\
\hline & & & $\begin{array}{l}\text { Lower } \\
\text { bound }\end{array}$ & $\begin{array}{l}\text { Upper } \\
\text { bound }\end{array}$ \\
\hline Apple & $3 e-{ }^{3}$ & $1.2 e^{-2}$ & 0 & $1.69 e^{-2}$ \\
\hline Lettuce & $2.5 e^{-2}$ & $5 e^{-2}$ & 0 & $1.12 \mathrm{e}^{-2}$ \\
\hline Potato & $5 e^{-3}$ or $1 e^{-2}$ & $-{ }^{a}$ & 0 & $5.6 e^{-3}$ \\
\hline Tomato & $2.5 e^{-2}$ & $5 e^{-2}$ & 0 & $1.23 e^{-2}$ \\
\hline Other food products ${ }^{b}$ & $\begin{array}{c}\text { Between } 1 \mathrm{e}^{3} \text { and } \\
2.5 \mathrm{e}^{2}\end{array}$ & $\begin{array}{c}\text { Between } 3 e-{ }^{3} \text { and } \\
5 e-{ }^{2}\end{array}$ & 0 & $6.49 \mathrm{e}^{2}$ \\
\hline
\end{tabular}

aAll samples were below the limit of detection (LOD).

bThe minimum limit of detection (LOD) was equal to $1 \mathrm{e}^{-3} \mathrm{mg} / \mathrm{kg}$ of fresh weight for meat, fish, seafood and dairy products. The maximum LOD was equal to $2.5 \mathrm{e}^{2} \mathrm{mg} / \mathrm{kg}$ of fresh weight for all vegetables excluding potatoes. The minimum limit of quantification (LOQ) was equal to $3 \mathrm{e}^{-3} \mathrm{mg} / \mathrm{kg}$ of fresh weight for merguez. The maximum LOQ was equal to $5 \mathrm{e}^{2} \mathrm{mg} / \mathrm{kg}$ of fresh weight for artichokes and turnips.

\section{References}

BNV-D (National Bank of Plant Protection Products Sales by Authorized Distributors). 2020. http://www.data.eaufrance.fr/jdd/bd45f801-45f7-4f8c-b128-a1af3ea2aa3e. Accessed 4 May 2020.

Chambres d'Agriculture Hauts-de-France (Hauts-de-France Agricultural Chambers). Chambre regional d'agriculture, Lille. 2020. https://hautsdefrance.chambres-agriculture.fr/voschambres/. Accessed 18 December 2020.

Davezac H, Grandguillot G, Robin A, Saoult C. L'eau potable en France 2005-2006. French Ministry for Health, Youth and Sports: Paris. 2008.

EFSA. The 2013 European Union report on pesticide residues in food. EFSA Journal. 2015;13 (3):4038; doi:10.2903/j.efsa.2015.4038.

Leblanc JC, coordination, Sirot V, coordination, et al. Étude de l'alimentation totale française 2 (EAT 2) - Tome 2. Agence nationale de sécurité sanitaire de l'alimentation, de l'environnement et du travail: Maisons-Alfort. 2011. French.

Synop Essentielles OMM. Synop Essential WMO Database. Météo-France, Saint-Mandé. 2020.

https://donneespubliques. meteofrance.fr/?fond=produit\&id produit=90\&id rubrique=32.

Accessed 17 Jun 2020. 
Figure 1

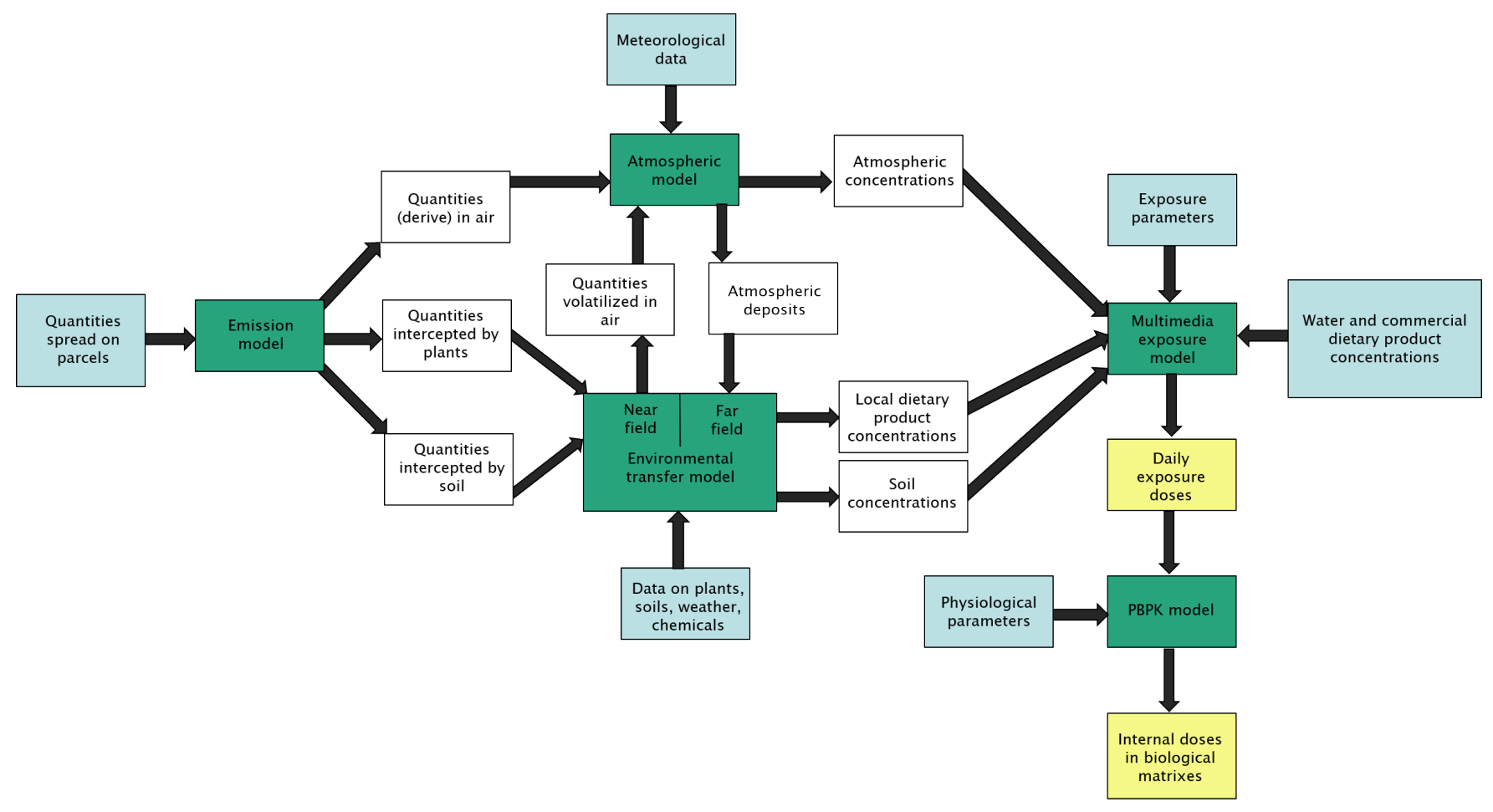

3

4

5

6

7

8

9

10

11

12

13

14 
Figure 2

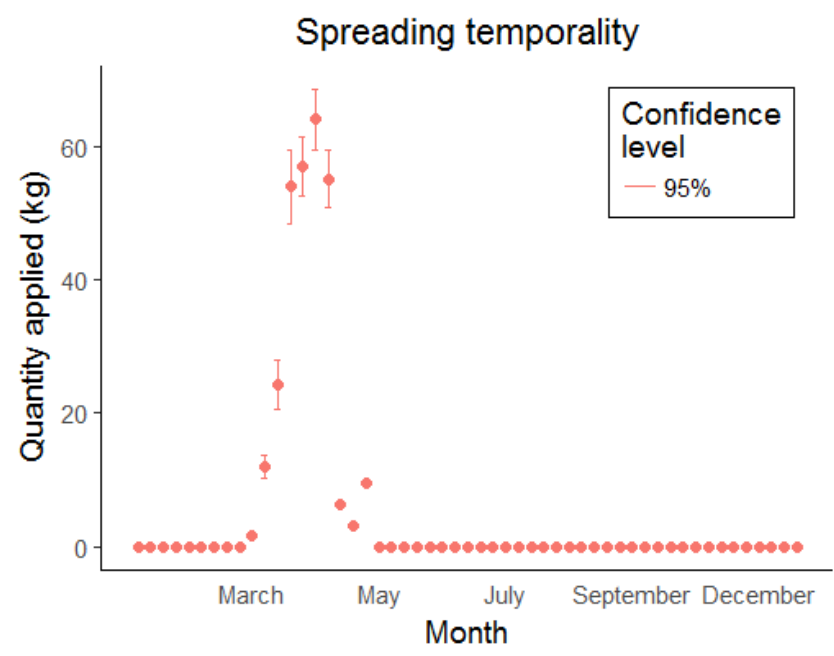




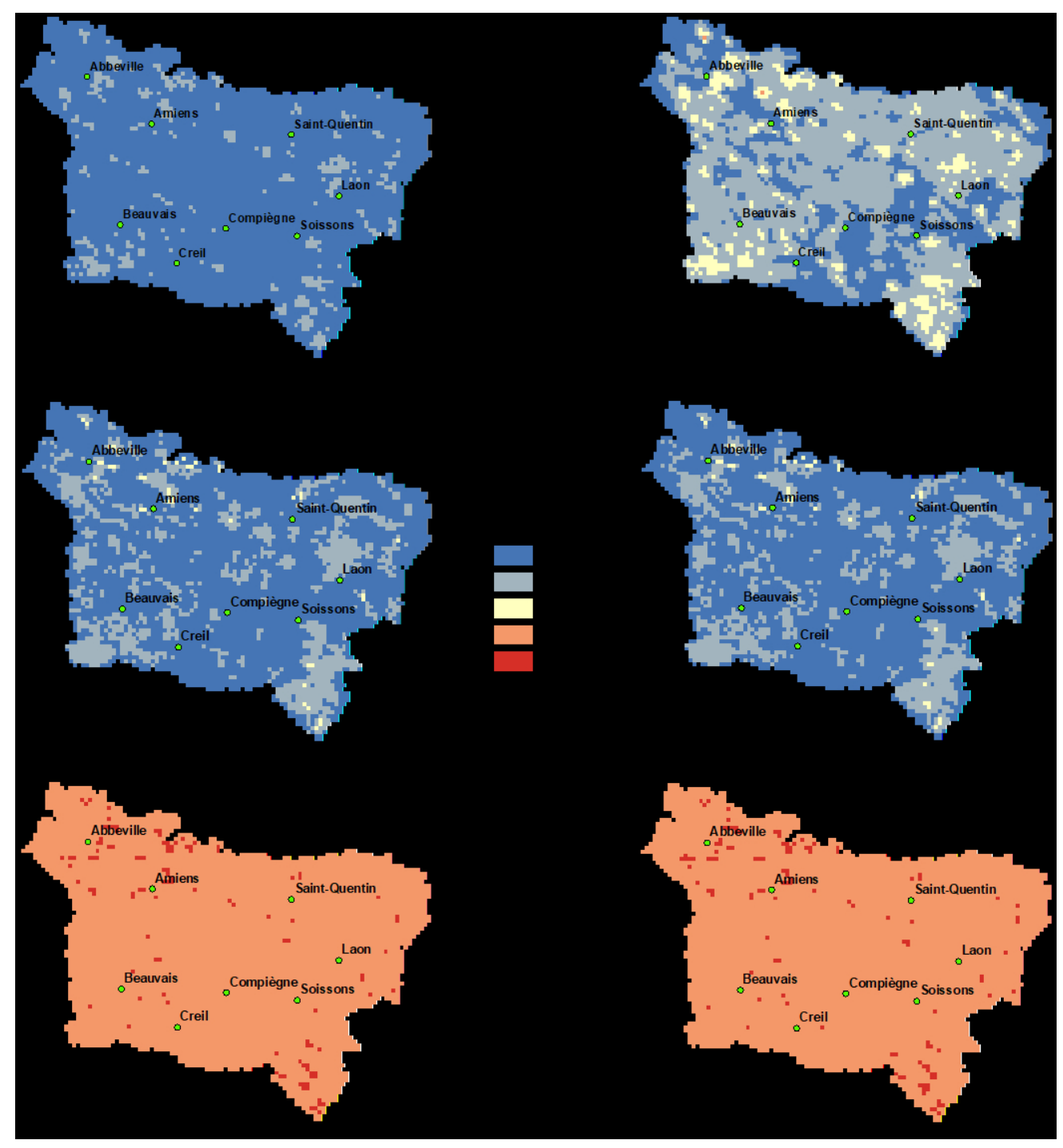


Figure 4
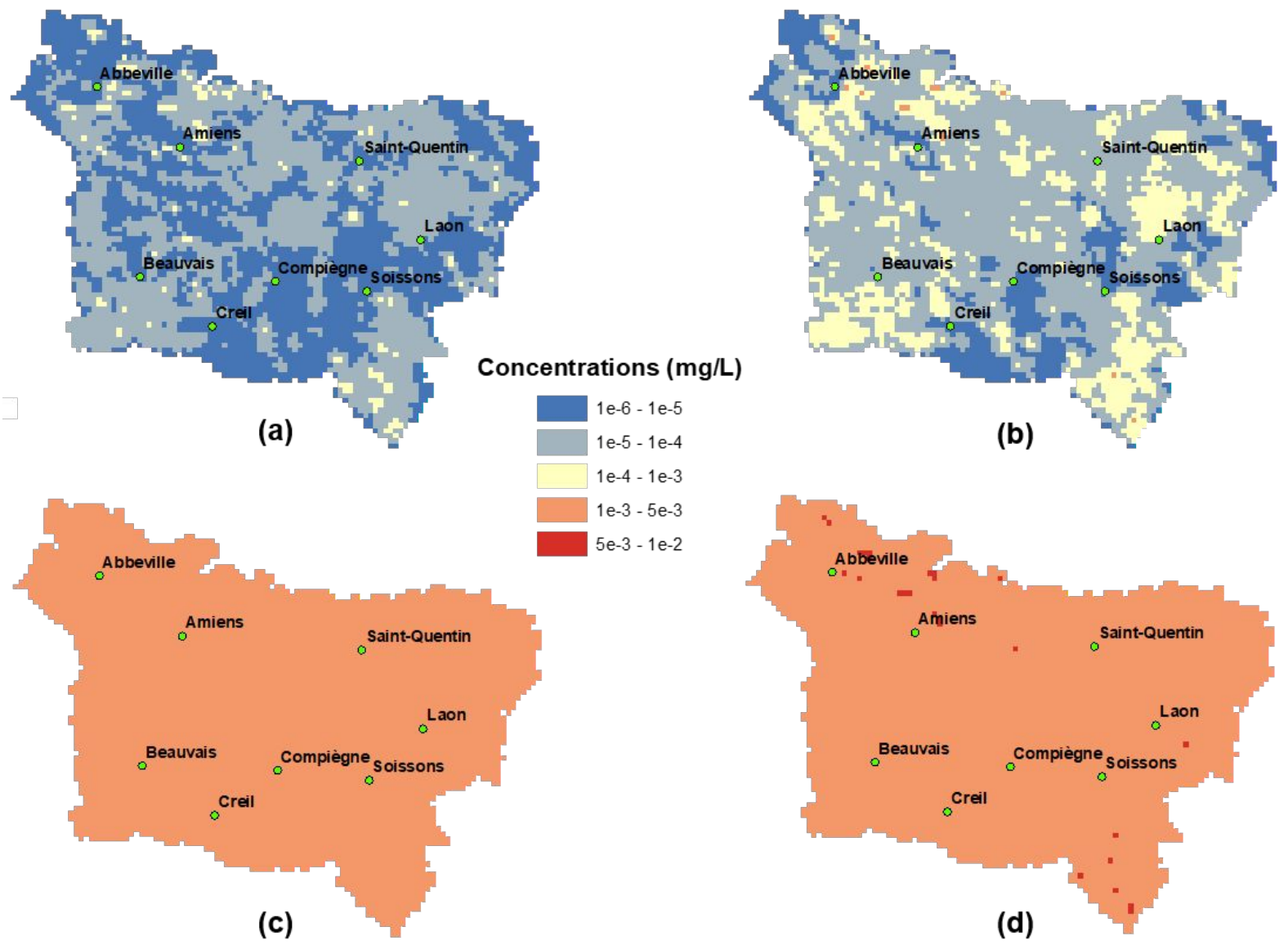
Page 39 of 39

Figure 5
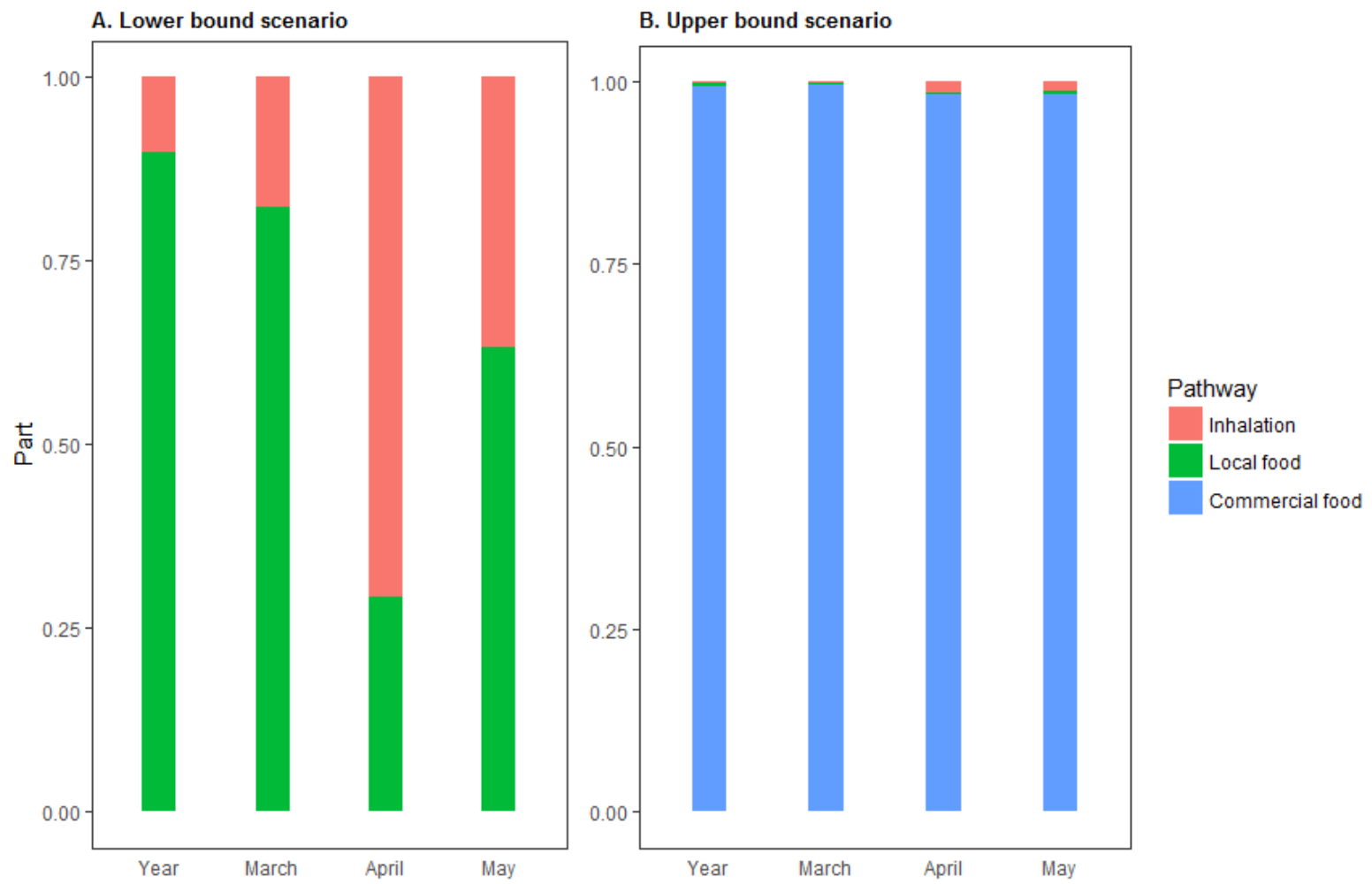